\title{
All-sky information content analysis for novel passive microwave instruments in the range from 23.8 to $874.4 \mathrm{GHz}$
}

\author{
Verena Grützun ${ }^{1}$, Stefan A. Buehler ${ }^{1}$, Lukas Kluft ${ }^{2}$, Jana Mendrok $^{3}$, Manfred Brath ${ }^{1}$, and Patrick Eriksson ${ }^{3}$ \\ ${ }^{1}$ Meteorologisches Institut, Fachbereich Geowissenschaften, Centrum für Erdsystem und Nachhaltigkeitsforschung (CEN), \\ Universität Hamburg, Bundesstraße 55, 20146 Hamburg, Germany \\ ${ }^{2}$ Max-Planck-Institut für Meteorologie, Bundesstraße 53, 20146 Hamburg, Germany \\ ${ }^{3}$ Department of Space, Earth and Environment, Chalmers University of Technology, 41296 Gothenburg, Sweden
}

Correspondence: Verena Grützun (verena.gruetzun@uni-hamburg.de)

Received: 20 October 2017 - Discussion started: 23 November 2017

Revised: 27 April 2018 - Accepted: 29 May 2018 - Published: 18 July 2018

\begin{abstract}
We perform an all-sky information content analysis for channels in the millimetre and sub-millimetre wavelength with 24 channels in the region from 23.8 to $874.4 \mathrm{GHz}$. The employed set of channels corresponds to the instruments ISMAR and MARSS, which are available on the British FAAM research aircraft, and it is complemented by two precipitation channels at low frequencies from Deimos. The channels also cover ICI, which will be part of the MetOp-SG mission. We use simulated atmospheres from the ICON model as basis for the study and quantify the information content with the reduction of degrees of freedom $(\triangle \mathrm{DOF})$. The required Jacobians are calculated with the radiative transfer model ARTS. Specifically we focus on the dependence of the information content on the atmospheric composition. In general we find a high information content for the frozen hydrometeors, which mainly comes from the higher frequency channels beyond $183.31 \mathrm{GHz}$ (on average 3.10 for cloud ice and 2.57 for snow). Considerable information about the microphysical properties, especially for cloud ice, can be gained. The information content about the liquid hydrometeors comes from the lower frequency channels. It is 1.69 for liquid cloud water and 1.08 for rain using the full set of channels. The Jacobians for a specific cloud hydrometeor strongly depend on the atmospheric composition. Especially for the liquid hydrometeors the Jacobians even change sign in some cases. However, the information content is robust across different atmospheric compositions. For liquid hydrometeors the information content decreases in the presence of any frozen hydrometeor, for the frozen hydrometeors it decreases slightly in the presence of the respective
\end{abstract}

other frozen hydrometeor. Due to the lack of channels below $183 \mathrm{GHz}$ liquid hydrometeors are hardly seen by ICI. However, the overall results with regard to the frozen hydrometeors also hold for the ICI sensor. This points to ICI's great ability to observe ice clouds from space on a global scale with a good spatial coverage in unprecedented detail.

\section{Introduction}

In the last few years, passive millimetre and sub-millimetre wavelength measurements of the cloudy sky from space have gained increasing attention. Especially frozen clouds are in the focus of such measurements. The reason being that clouds are an important factor in the climate system. For decades clouds have contributed to the largest uncertainties in estimating the Earth's changing energy budget (Boucher et al., 2013). Also, the assimilation of the cloudy sky in numerical weather forecasting is becoming increasingly important (Guerbette et al., 2016; Geer et al., 2017). To constrain the estimation of the future development of the climate system and to assimilate the cloudy sky into the weather forecast, reliable global observations of clouds are required. Passive millimetre and sub-millimetre wavelength measurements have a great potential to fill that gap.

Many studies have investigated the performance of setups, which employ channels in the range from 5 to $874 \mathrm{GHz}$. For example, Di Michele and Bauer (2006) focus on channels between 5 and $200 \mathrm{GHz}$. They find different suitable frequency bands for rain over ocean, snow over land and ocean 
and clouds over ocean and suggest several channels covering these frequency ranges for global and multi-seasonal applications. Jiménez et al. (2007) investigated an instrument with 12 channels around the 183,325 and $448 \mathrm{GHz}$ water vapour lines and the 234, 664 and $874 \mathrm{GHz}$ window channels. A fivereceiver instrument dropping one of the two highest channels proved to be equally powerful in a mid-latitude scenario as the all-receiver instrument; however, for tropical scenarios the highest channel reduced the error for very thin and high clouds. Also, new studies investigate the potential for assimilating microwave sounding data from geostationary satellites into numerical forecast models to further improve these models (Duruisseau et al., 2017).

There are already very successful ongoing missions, which, amongst other things, observe clouds from space. A well-known instrument, which has been observing the atmosphere from space for decades now, is the Advanced Microwave Sounding Unit B (AMSU-B, Weng et al., 2003; Zhao and Weng, 2002) and its successor, the Microwave Humidity Sounder (MHS, Bonsignori, 2007). AMSU-B and MHS operate with five channels in the range from 89 to $190 \mathrm{GHz}$, respectively. Although the instruments are primarily designed as humidity sounders, as a side product they also allow for an observation of the ice water path (column integrated ice water mass), rain rate and snow water equivalent.

In the near future, the Meteorological Operational Satellite - Second Generation (MetOp-SG, Pica et al., 2012) with the new Ice Cloud Imager (ICI) will be launched. The principle of ICI is explained in the CloudIce mission proposal for ESA's Earth Explorer 8 (Buehler et al., 2007, 2012). ICI has in total 11 channels in the range from 183.31 to $664.0 \mathrm{GHz}$ and will provide several ice retrievals including the ice water path and the cloud ice effective radius. It will be flown together with the MicroWave Imager (MWI), which has 18 channels in the range from 18.7 to $183.31 \mathrm{GHz}$ (see e.g. Accadia et al., 2013, for detailed information about ICI and MWI). The inclusion of the low channels in these instruments allows for precipitation retrievals.

In recent years, the potential of hyper-spectral sensors in the millimetre and sub-millimetre wavelength region has been explored for clear-sky (Aires et al., 2015; Mahfouf et al., 2015) and cloudy-sky (Birman et al., 2017; Aires et al., 2018) conditions. Birman et al. (2017) find that the information content on hydrometeors can be significantly increased by using a hyper-spectral sensor, but also depends on the assumed microphysical properties of the frozen hydrometeors.

The different hydrometeor types have different effects on the measurement channels. Several studies focused on the influence of clouds and precipitation on AMSU-like channels around 89, 150 and $183.31 \mathrm{GHz}$ (e.g. Hong et al., 2005; Sreerekha et al., 2008, and references therein). It was found that high level clouds with high cloud tops cause a brightness temperature depression in the channels with frequencies greater than $150 \mathrm{GHz}$. Low level clouds have only a marginal effect on the $183.31 \mathrm{GHz}$ channel because the largest sensi- tivity of that channel is too high up in the atmosphere (Burns et al., 1997; Bennartz and Bauer, 2003). For the same reason, the surface emissivity does not contribute to the signal in these channels. The channel at $89 \mathrm{GHz}$ on the other hand is influenced by altostratus liquid clouds (Muller et al., 1994). Furthermore it is very sensitive to the surface emissivity. Even though the channel at $150 \mathrm{GHz}$ is also a window channel, it shows much less sensitivity to the surface because the region with highest sensitivity to changes in the atmospheric column is located in the lower troposphere above the surface (Bennartz and Bauer, 2003; Hong et al., 2005). The Megha-Tropiques mission (megha is the Sanskrit word for clouds, tropiques the French word for tropics, Desbois et al., 2002; Karouche et al., 2012) also allows an ice cloud content profile retrieval from the Microwave Analysis and Detection of Rain and Atmospheric Systems (MADRAS sensor, e.g. Defer et al., 2014) with channels at 89 and $157 \mathrm{GHz}$. Greenwald and Christopher (2002) found that precipitating cold clouds give a much stronger signal in channels near $183.31 \mathrm{GHz}$ compared to cold clouds which are not precipitating. They question the applicability of channels near or below $183.31 \mathrm{GHz}$ to gain quantitative estimates of physical properties of non-precipitating ice clouds from space.

In fact, it is very likely that the presence of one hydrometeor type affects the observation of another in the passive observation in the millimetre and sub-millimetre range. The reason is that the signal, which is observed at the top of the atmosphere by the satellite is a result of the interaction of the radiation with each atmospheric component present in the pathway. In this article, we specifically focus on this effect in detail. In the following, we study the information content of passive microwave measurements of clouds from space with specific focus on the cloudy atmosphere, especially on frozen hydrometeors. We investigate whether it depends on the combinations of cloud and precipitation hydrometeors within the atmospheric column how much information is obtained, as the results from Greenwald and Christopher (2002) suggest. To include higher channels, which may be suitable to detect ice microphysical properties, we chose the setup of the instruments MARSS (Microwave Airborne Radiometer Scanning System, McGrath and Hewison, 2001) and ISMAR (International Sub-millimetre Microwave Airborne Radiometer, Fox et al., 2017) and complement them by two low channels at 23.8 and $50.1 \mathrm{GHz}$ from Deimos (Dual-frequency Extension to In-flight Microwave Observing System, Hewison, 1995). These instruments cover a large range of microwave channels from 23.8 to $874.4 \mathrm{GHz}$ (see Sect. 5.1), including the ICI channels, and part of MWI. Thus, we can put the focus on the potential of novel instruments operating at frequencies higher than $183 \mathrm{GHz}$ to robustly observe ice, but also include liquid clouds and precipitation, which are observed with the channels lower than $183 \mathrm{GHz}$.

Since it is impossible to have full knowledge of the real atmosphere, we chose to base our investigations on highresolution model data from the ICOsahedral Non-hydrostatic 
model (ICON model, Dipankar et al., 2015; Heinze et al., 2017), which employs the two-moment microphysics by Seifert and Beheng (2006). We use the reduction of degrees of freedom as a tool to quantify the information content of a measurement with regard to a certain hydrometeor. For this purpose we require Jacobians, which we explicitly calculate with the Atmospheric Radiative Transfer Simulator (ARTS, Buehler et al., 2005, 2018; Eriksson et al., 2011). We first use an idealized mean profile to perform a conceptual study of the mechanisms and then look into a larger set of atmospheric profiles from ICON with the full set of channels and with the channel set corresponding to ICI to investigate if the results hold for more realistic atmospheres.

In the following, firstly the underlying modelling framework is introduced in Sect. 2. Secondly, the microphysical assumptions for the atmospheric and for the radiative transfer model, which we use in this study are introduced in Sect. 3. The framework to quantify the information content is presented in Sect. 4. We explain the choice of an idealized atmospheric profile and of 90 realistic profiles, as well as the selected set of channels in Sect. 5. The results are presented in Sect. 6. Finally, we conclude the article in Sect. 7.

\section{Models}

\subsection{ICON}

This study is based on data from the novel ICOsahedral Nonhydrostatic model (ICON model, e.g. Wan et al., 2013; Dipankar et al., 2015). We use a simulation of a frontal case on 26 April 2013 over western Germany with rapidly increasing cloudiness developing to a completely overcast situation in the afternoon. Several light to medium rain showers occurred during that day, and ice clouds as well as snow in the upper atmospheric layers were observed. The case represents a spring day in the northern mid-latitudes. Choosing a tropical case or a much drier case, for example in the Arctic, will have an effect on both the Jacobians and the resulting information content. The Jacobians will peak at different heights, and the channels will observe the hydrometeor content depending on how far down they penetrate the atmosphere. Nevertheless, the principles of the observation and the interdependencies of the Jacobians can be made clear at the hand of this case.

The ICON simulation has a horizontal resolution of $650 \mathrm{~m}$ with 50 hybrid terrain-following vertical height levels to $22 \mathrm{~km}$. It was performed in the framework of the BMBF project High Definition Clouds and Precipitation for advancing Climate Prediction $\left(\mathrm{HD}(\mathrm{CP})^{2}\right)$ and was provided by the Max Planck Institute for Meteorology, Hamburg. The simulation complements the measurement campaign HOPE $\left(\mathrm{HD}(\mathrm{CP})^{2}\right.$ Observation Prototype Experiment, Macke et al., 2017), which took place in April and May 2013 around Jülich in western Germany and focused on clouds and model eval- uation (e.g. Stamnas et al., 2016; Heinze et al., 2017; Macke et al., 2017) ${ }^{1}$.

\subsection{Atmospheric Radiative Transfer Simulator (ARTS)}

In order to perform an information content analysis a radiative transfer model is required to simulate the satellite measurements and the respective height-resolved Jacobians based on the atmospheric profiles simulated by ICON. We use the Atmospheric Radiative Transfer Simulator (ARTS, Buehler et al., 2005, 2018; Eriksson et al., 2011, version 2.3.296). ARTS is an open source detailed line-by-line radiative transfer model for microwave to thermal infrared radiation, which is capable of simulating polarized radiative transfer in all spatial geometries ${ }^{2}$. ARTS offers analytical Jacobians for trace gas concentration, and semi-analytical Jacobians for temperature. In this ARTS version, Jacobians for hydrometeor parameters are calculated by perturbation, which has higher computational costs compared to analytical computation. Details about the calculation of these Jacobians are given in Sect. 4.1. The specific setup of ARTS is described in Sect. 3.2.

The radiative transfer simulations were performed with two different surface emissivities $\epsilon$. In the first set of simulations, $\epsilon$ is equal to 0.6 , which corresponds to an ocean surface. In the second set of simulations, $\epsilon$ is equal to 0.9 , which corresponds to a land surface. Further, specular reflection is assumed. One should keep in mind though, that in reality $\epsilon$ depends strongly on the specific surface and to a smaller extent on the channel. However, the results differ only little for the different emissivities. Therefore, we use the simplified assumption of a constant emissivity for all channels, and the main part of the results shown in this article will be for the emissivity of the ocean, i.e. $\epsilon=0.6$.

\section{Microphysical parameterizations}

\subsection{ICON}

ICON uses the two-moment microphysical scheme by Seifert and Beheng (2006), which offers more detailed information about the cloud microphysical properties than the commonly used one-moment bulk schemes. It simulates the mass mixing ratio $(M)$ and number mixing ratio $(N)$ of cloud liquid water, cloud ice, rain, snow, hail and graupel. As only very little graupel and hail was found in the simulation, we disregard them in the following. For the atmospheric radiative

\footnotetext{
${ }^{1}$ Details about the project and the campaign can be found on the project homepage http://hdcp2.eu (last access: July 2017) or on the data base SAMD (Standardised Atmospheric Measurement Data) homepage hosted at the Integrated Climate Data Center (ICDC) under http://icdc.cen.uni-hamburg.de/1/projekte/samd.html (last access: April 2018).

${ }^{2}$ See www.radiativetransfer.org (last access: 15 June 2018) for documentation and download.
} 
Table 1. Distribution parameters for the hydrometeor particles as put forth by Seifert and Beheng (2006) and Axel Seifert (personal communication, 2014).

\begin{tabular}{lrr}
\hline $\begin{array}{l}\text { Hydrometeor } \\
\text { type }\end{array}$ & $v$ & $\mu$ \\
\hline LWC & 1 & 1 \\
RWC & 0 & $1 / 3$ \\
IWC & 0 & $1 / 3$ \\
SWC & 0 & $1 / 2$ \\
Graupel & 1 & $1 / 3$ \\
Hail & 1 & $1 / 3$ \\
\hline
\end{tabular}

transfer simulator ARTS (Sect. 2.2) the mass mixing ratios (unit $\mathrm{kg} \mathrm{kg}^{-1}$ ) were converted to mass densities $\left(\mathrm{kg} \mathrm{m}^{-3}\right)$ by multiplying with the density of the atmosphere.

In the following, we refer to liquid cloud water mass density (liquid water content) as LWC, to cloud ice mass density as IWC, to rain mass density as RWC and to snow mass density as SWC. We refer to LWC and RWC as liquid hydrometeors and to IWC and SWC as frozen hydrometeors. The respective column integrated quantities, i.e. the paths are denoted as LWP (cloud liquid water path), IWP (cloud ice water path), RWP (rain water path) and SWP (snow water path). Note that even though the ICON model's microphysical parameterization requires a clear distinction between suspended and precipitating hydrometeors in each grid box, i.e. between LWC and RWC or IWC and SWC, this distinction can not be made in reality. Nevertheless we will discuss the cloud and precipitating hydrometeors separately in the remainder of the article, always keeping in mind that, in reality, there is a smooth transition between the cloud and precipitation hydrometeors.

For the simulation of the cloud radiative effect the size distribution and shape of the hydrometeors in terms of the massdimension relationship are of high importance. It is crucial to match the microphysical parameterizations of the radiative transfer model with those of the atmospheric model, especially the size distribution.

The size distribution in the two-moment scheme by (Seifert and Beheng, 2006) is based on the hydrometeor mass. It employs a modified $\Gamma$-distribution with two free parameters as particle size distribution functions for each hydrometeor type. It is defined as follows:

$f(m)=A m^{v} \exp \left(-\lambda m^{\mu}\right)$,

where the independent size parameter is the particle mass $m$. The distribution parameters are $A, v, \lambda$ and $\mu$ and have to be provided by the scheme. In the actual version of Seifert and Beheng (2006)'s scheme, $v$ and $\mu$ are fixed for each hydrometeor type (Table 1) and $A$ and $\lambda$ are calculated prognostically (see Seifert and Beheng, 2006 for details of the calculation).

The size distributions from the two moment scheme for an idealized mean profile (purple) and a set of 90 individual

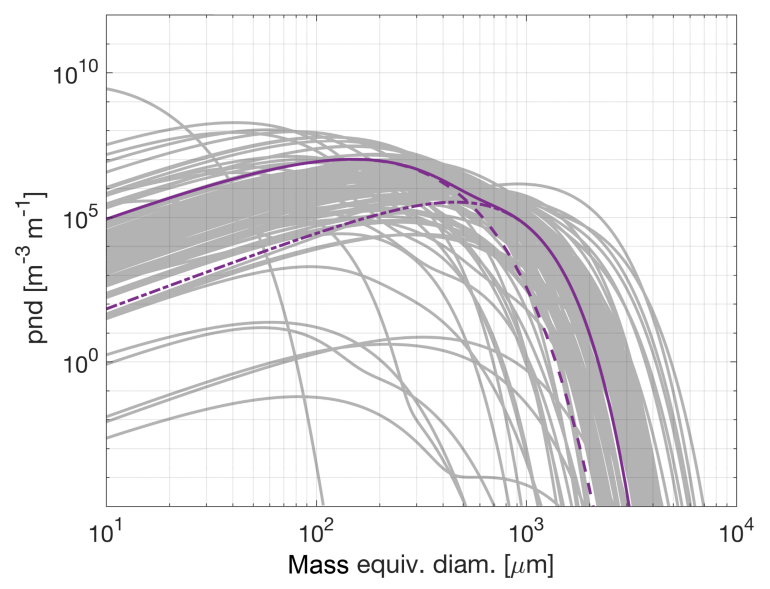

Figure 1. Size distributions for the idealized mean profile (purple) and 90 simulated profiles (grey) derived from ICON at $550 \mathrm{hPa}$ each. The sum of the distributions for IWC and SWC is shown for all profiles, and the individual distributions for IWC (dashed) and SWC (dash-dotted) are shown for the mean profile.

ICON profiles (grey) are shown in Fig. 1 (for the definition of the idealized and the 90 profiles please refer to Sect. 5.2). Note that the distributions are height dependent. They are shown at a height of $550 \mathrm{hPa}$, where both IWC and SWC exist in considerable amounts. The curves illustrate the sum of the distributions for IWC and for SWC, i.e. all frozen hydrometeors. For the mean profile, also the individual distributions for IWC and SWC are shown to illustrate to what extent they overlap. The two peaks, which are evident in the idealized and in some of the 90 profiles, result from the two different types of frozen hydrometeors. The one at smaller diameters belongs to IWC, the one at larger diameters belongs to SWC. As opposed to one-moment schemes, in which the distinction between IWC and SWC is done through a size threshold, in the two-moment scheme the distinction between IWC and SWC is done via the processes a particle has undergone. A particle is counted as snow if it has, for example, collided and joined with other hydrometeors (e.g. self-collection or collection of smaller hydrometeors). Single ice crystals are counted as cloud ice. Therefore, in the two moment-scheme cloud ice hydrometeors can be quite large in mass equivalent diameter and overlap with snow.

It is noteworthy that different schemes provide different size distributions. Compared to, for example, frozen hydrometeor size distributions for tropical cirrus clouds by McFarquhar and Heymsfield (1997) (not shown), in the twomoment scheme the number densities for small ice particles are orders of magnitude smaller. Apart from the different meteorological situation, this is mainly due to the fact that processes creating small ice particles in the two-moment scheme are missing (Axel Seifert, personal communication, 2016). However, aircraft measurements have been criticized for having too many small particles due to shattering (e.g. Heyms- 
field, 2007) and the exact amount of smaller particles remains uncertain. For the millimetre and sub-millimetre range this is not critical because the sensitivity to particles smaller than $100 \mu \mathrm{m}$ is small in this range (Eriksson et al., 2008).

It should be noted that aside from the differences in the size distribution also the mass-dimension relationship is a crucial ingredient for radiative transfer modelling (e.g. Eriksson et al., 2015). However, atmospheric models only implicitly assume such a relationship, for example to parameterize collision or fall speeds. Also, normally atmospheric models have no detailed information about the particle shape. Furthermore, different ice habits within one hydrometeor type (cloud ice, snow, hail or graupel) are not considered. This will introduce some errors in both the microphysical calculations of ICON and the radiative transfer simulations. A perfect matching of the atmospheric model and the radiative transfer model with regard to particle shape and habit would require more sophisticated assumptions in the atmospheric model.

\subsection{ARTS}

The hydrometeor size distributions of the particles have been implemented in a discretized form into ARTS using the same distribution function as the two-moment scheme from Seifert and Beheng (2006). As a second variable representing the microphysical characteristics of the hydrometeors the particle mean mass $\bar{m}$ was chosen. It was calculated by dividing the mass mixing ratio $M$ by the number mixing ratio $N$, both taken from ICON. This has the advantage that the mass density Jacobians for a fixed particle mean mass (as opposed to a fixed particle number mixing ratio) correspond to the ones one would get from a one-moment bulk scheme. However, in the remainder of the article we will focus on the mass densities and only include the values for the mean particle masses $\bar{m}$ in the final results for the information content to see if the channels higher than $183 \mathrm{GHz}$ (see Sect. 5.1 for chosen set of channels) have a potential to measure cloud microphysical parameters such as hydrometeor size.

The scattering properties for the different hydrometeor types are defined as in Geer and Baordo (2014). For LWC and RWC, spherical particles are assumed and for IWC soft spheres with a density of $900 \mathrm{~kg} \mathrm{~m}^{-3}$ are assumed. For spherical particles, the single scattering properties were calculated with Mie theory, using the program by Mätzler (2002). For SWC, the scattering properties were taken from the database of Liu (2008) assuming sector-like snowflakes for channels up to and including $334 \mathrm{GHz}$ and the data base of Hong et al. (2009) assuming aggregates for channels higher than that. Since the original Hong et al. (2009) database assumes a constant effective density for the aggregates and is also based on the earlier Warren (1984) refractive index we use a corrected version of the database, in which the absorption is rescaled using the Mätzler (2006) parameterization for the refractive index of ice. Rescaling is done by multiplication with $\operatorname{imag}(n) / \operatorname{imag}\left(n_{0}\right)$, where $n$ and $n_{0}$ are the refractive indices from Warren (1984) and Mätzler (2006), respectively. The rescaling to obtain data for $183,213,243$ and $266 \mathrm{~K}$ was applied. The scattering extinction and the phase matrix remain unchanged, which means that the rescaling only applies to the absorption (see Brath et al., 2018 for details).

We use the Discrete Ordinate ITerative (DOIT, Emde et al., 2004) method to calculate the scattering within ARTS. The Planck brightness temperatures were calculated for all side bands within the chosen set of channels (see Sect. 5.1). We do not use an explicit sensor response function but perform monochromatic radiative transfer simulations for the centre frequencies of the side bands in each channel and use the mean of the two brightness temperatures. For clear sky, highly resolved (in terms of frequencies) tests showed that the error compared to this simplified treatment is less than $1 \mathrm{~K}$ (Brath et al., 2018). As the scattering properties of the hydrometeors change only marginally within the band width, a further increase of this uncertainty in the cloudy case is unlikely. A pencil beam with an incidence angle of $65^{\circ}$ at the ground was used. For gas absorption we use the HITRAN (HIgh-resolution TRANsmission molecular absorption, Rothman et al., 2013) database, the MT_CKD model (Mlawer et al., 2012) version 2.52 for the continuum absorption of water vapour and the MT_CKD model version 1.00 for the continuum absorption of oxygen.

\section{Reduction of degrees of freedom}

In principle, an information content analysis quantifies the information that is obtained from a measurement with a certain set of channels. The information leads to the reduction of the a priori error: the larger the information content, the larger the reduction. A quantification of the information is, for example, possible through calculating the reduction of the degrees of freedom $(\triangle \mathrm{DOF})$ for the analysis compared to the a priori state, or through calculating the entropy $S$ of the two states (e.g. Rodgers, 2011; Di Michele and Bauer, 2006). In this study we use the reduction of the degrees of freedom $\triangle \mathrm{DOF}$, which is defined by

$$
\Delta \mathrm{DOF}=\operatorname{trace}\left(\mathbf{I}-\mathbf{S}_{\mathrm{r}} \mathbf{S}_{\mathrm{a}}^{-1}\right),
$$

with the unity matrix $\mathbf{I}$, the a priori covariance matrix $\mathbf{S}_{\mathrm{a}}$ and the a posteriori, or analysis error covariance matrix $\mathbf{S}_{\mathrm{r}}$. $\mathbf{S}_{\mathrm{r}}$ is defined according to the optimal estimation method as the reciprocal sum of the a priori and measurement error $\mathbf{S}_{y}$ :

$\mathbf{S}_{r}=\left(\mathbf{S}_{\mathrm{a}}^{-1}+J^{T} \mathbf{S}_{y}^{-1} J\right)^{-1}$.

$\mathbf{S}_{y}$ is transformed from measurement space into state space with the transpose of the Jacobian $J$. We set the measurement error to $1 \mathrm{~K}$ for each channel and assume that it is uncorrelated between channels, therefore $\mathbf{S}_{y}$ is a diagonal matrix 
with $1 \mathrm{~K}^{2}$ on the diagonal. Furthermore, a perfect forward operator is assumed, since the focus of this study is mainly the interdependency of the information content for different hydrometeors within the atmospheric column. More realistic choices for the error of the forward operator are discussed for example in Aires et al. (2018). The assumptions made for $\mathbf{S}_{a}$ are described further below in Sect. 4.2.

If the analysis error after the measurement is equally large as the a priori error before, $\triangle \mathrm{DOF}$ is zero and no information was gained. The closer the analysis error is to zero, the larger $\triangle \mathrm{DOF}$ is, with a maximum (in reality unreachable) value equal to the number of channels, in our case 24 . $\triangle \mathrm{DOF}$ can also be interpreted as pieces of information. If we have one piece of information one quantity can be retrieved, for example the hydrometeor path. If we have two pieces, two quantities can be obtained, for example the hydrometeor mass in two different heights.

For the analysis, the portion of the information content is needed that is associated with the specific hydrometeors. The method we chose is a linear splitting of the trace in the definition of $\triangle \mathrm{DOF}$ to the block matrices that correspond to the respective quantity $\left(\mathrm{H}_{2} \mathrm{O}\right.$, IWC, LWC, SWC, RWC and the respective hydrometeor mean masses). However, we would like to stress that this is an approximation and does not consider the cross-correlations between the various hydrometeors.

\subsection{Jacobians}

The calculation of the Jacobians by explicit perturbation (in contrast to the analytical calculation) $J$ generally requires three steps: first, calculate the brightness temperature $T_{\mathrm{B}}^{\mathrm{c}}$ for a specific channel $\mathrm{c}$ for the unperturbed atmosphere. Second, perturb one atmospheric quantity $x$, for example IWC, by a perturbation $\delta$ and again simulate the perturbed brightness temperature $\left[T_{\mathrm{B}}^{\mathrm{c}}\right]_{\delta}$ for that channel. Third, divide the difference of the two brightness temperatures by the perturbation. If, as in our analysis, height resolved Jacobians are required, the perturbation has to be applied successively to each of the height levels $k$. Note that a perturbation at a distinct height level $k$ strictly speaking means a perturbation of the respective quantity at the two adjacent height layers which the radiation passes through.

The Jacobian $J_{c, k}$ at height $k$ and for a channel $\mathrm{c}$ is thus given by the following equation:

$J_{c, k}=\frac{\left[T_{\mathrm{B}}^{\mathrm{c}}\right]_{k, \delta}-T_{\mathrm{B}}^{\mathrm{c}}}{\delta}$

with $\left[T_{\mathrm{B}}^{\mathrm{c}}\right]_{k, \delta}$ as the simulated brightness temperature if the quantity $x_{k}$ is perturbed, which denotes the value of $x$ at the height level $k$.

For the analysis, we define $\delta$ as a relative perturbation of $x_{k}$, as opposed to using an absolute value that is independent of the specific value of the $x_{k}$. This is especially useful for the calculation of Jacobians for the hydrometeor profiles.
First, the values of $x$ over height span several orders of magnitude. The use of a relative perturbation ensures that the perturbation is always small compared to the original value, and linearity can be assumed. Second, the hydrometeor profiles are discontinuous and do not exist at all heights. Using the relative perturbation ensures that only that part of the profile where hydrometeors exist in the first place is perturbed. We use $\delta=1 \%$ for each quantity (including water vapour, which in the following is referred to as $\mathrm{H}_{2} \mathrm{O}$ ) and at all heights.

Relative Jacobians also correspond to the retrieval of a quantity in logarithmic space. Regarding $1+\delta$ as the development of the natural logarithm for small $\delta$ it can be shown that $\delta=\ln \left(x_{k, \delta}\right)-\ln \left(x_{k}\right)=\Delta \ln x_{k}$, with $x_{k}$ as unperturbed value at height level $k$ and $x_{k, \delta}$ as perturbed value. The Jacobian then is as follows:

$J_{\mathrm{c}, k}=\frac{\left[T_{\mathrm{B}}^{\mathrm{c}}\right]_{k, \delta}-T_{\mathrm{B}}^{\mathrm{c}}}{\Delta \ln \left(x_{k}\right)}$.

As stated above, this corresponds to a retrieval in natural logarithm space. In the remainder of the article, we will stay in the framework of a logarithmic retrieval entirely.

The Jacobians for each of the two sidebands (see Sect. 5 for the definition of channels and side bands) were calculated and the mean of the two Jacobians was used for the subsequent analysis. We use the same height grid in ARTS as in the ICON simulation. The Jacobians for the $\mathrm{H}_{2} \mathrm{O}$ volume mixing ratio (VMR), the hydrometeor mass densities $M$ and the hydrometeor mean mass $\bar{m}$ were calculated. For the analysis, Jacobians were used in units of $\mathrm{K}(100 \%)^{-1}$ as calculated by ARTS. For the purpose of showing them in the following sections, they are normalized by the height layer thickness. Note that the height layers broaden with increasing height. This yields the unit $\mathrm{K}(\% \mathrm{~km})^{-1}$, which appears in the plots. Thus, the comparability of the Jacobians at different height levels is ensured. However, all calculations have been performed on the unnormalized values.

Note that Eqs. (4) and (5) only conceptually describe the Jacobian calculation. In practice, we do not make a fully independent $T_{\mathrm{B}}$ calculation for each perturbation, since this is computationally very inefficient for the iterative scattering solver used (Emde et al., 2004). Instead, the scattering solver uses the result from the unperturbed scheme as a starting point. That result should be close to the result from the perturbed case already, because the profile perturbations are small. From that starting point, the perturbed Jacobians are calculated with far fewer iterations compared to a completely uneducated starting point, which makes the scheme far more computationally efficient.

\subsection{A priori covariance}

The final component necessary to calculate the information content of a measurement is the a priori covariance error matrix $\mathbf{S}_{\mathrm{a}}$. In the ICON model framework, the matrix can be calculated directly from the model data as the covariance of 
the different quantities on different height levels. This means that we take the model mean state as a priori state, and the full variability of the model on the chosen domain (state domain) and simulation time as its uncertainty.

Certain assumptions have to be made in order to calculate the a priori covariance. First, only cloudy cases are considered. We assume that some kind of cloud detection has been done prior to the observation of the cloudy sky. To identify cloudy cases in the model, a threshold for the total condensed water path is applied, i.e. for the sum of the paths of all hydrometeors. We use the approximate detection threshold of $10^{-4} \mathrm{~kg} \mathrm{~m}^{-2}$. If the total water path exceeds that threshold, the corresponding profile is used in the calculation of the a priori error covariance.

Since relative Jacobians (see Sect. 4.1) were used, i.e. a retrieval in natural logarithm space, also the covariance needs to be calculated in ln space. To enable this calculation, zero values have to be removed from the hydrometeor profiles. For this purpose we set a threshold for each quantity for which the a priori error covariance is calculated. The choice of this threshold is a non-trivial task, and the threshold will affect the desired information content. We will address this in more detail in the respective result section. The smaller the threshold is, the larger the a priori variance is and the more information an observation will provide in comparison.

$\mathrm{H}_{2} \mathrm{O}$ is smooth and, above all, continuous. Therefore the numerical model threshold $10^{-20} \mathrm{~kg} \mathrm{~m}^{-3}$ is used for it. For the hydrometeor mass densities $10^{-7} \mathrm{~kg} \mathrm{~m}^{-3}$ is used. If we assume a detection limit for the water path of $1 \mathrm{~g} \mathrm{~m}^{-2}$ and a cloud thickness in the order of $1 \mathrm{~km}$, then this value for the local mass density is a little bit smaller than the detection limit, depending on the real cloud thickness. Furthermore, that mass density threshold value is close to an internal threshold within the two-moment microphysics scheme (close, because the microphysics scheme employs mixing ratios instead of mass densities). For example, if the mass density of cloud ice is larger than that threshold, collisional growth can take place (Axel Seifert, personal communication, 2017). For the mean masses of the different hydrometeors, separate minimum values are used in the two-moment scheme. The thresholds employed are $4.2 \times 10^{-15} \mathrm{~kg}$ for cloud liquid water mean mass, $10^{-12} \mathrm{~kg}$ for cloud ice mean mass, $2.6 \times 10^{-10} \mathrm{~kg}$ for rain mean mass, and $10^{-10} \mathrm{~kg}$ for snow mean mass. The same thresholds for the mean masses were used in the calculation of the a priori error covariance. The chosen thresholds furthermore ensure that the relevant peaks, within the mass density distributions for LWC, RWC, IWC and SWC, which constitute the clouds or precipitation, are covered. The peaks are roughly located at -4.2 with a width of 0.7 in units of the decadal logarithm (LWC), -5.3 with a width of 0.8 (IWC), -5.0 with a width of 0.8 (RWC) and at -5.3 with a width of 0.9 (SWC). Therefore they are all well above $10^{-7}$, which was chosen as threshold. Because for the mean masses we used the model inherent thresholds for the distribution, this is naturally true for the mean masses of all hydrometeors as well (not shown). We are aware that those choices affect the results for the information content. It will be discussed further in Sect. 6.3.

Figure 2 shows the a priori covariance in $\ln$ space and the corresponding correlation matrix defined as $\mathbf{C}_{i, j}=$ $S_{i, j} / \sqrt{S_{i i} S_{j j}}$. The 25 block matrices give the covariance and correlation of pairs of model variables on their 49 height levels. Note that we have to skip the uppermost 50th height level from ICON because ARTS requires one level on top of the "cloud box", which defines the cloudy area where scattering is calculated. Since the matrices are symmetric, only the lower triangle is shown for clarity.

The covariance naturally is largest at the height levels where hydrometeors reside and goes up to 12.2 in units of the natural logarithm on the diagonal of the LWC $\times$ LWC block matrix. For the other hydrometeors, the maximum reaches almost eight on the diagonal. The covariance for $\mathrm{H}_{2} \mathrm{O}$ is small compared to the one for hydrometeors (smaller than one). This reflects the much lower variability and smaller dynamical range of $\mathrm{H}_{2} \mathrm{O}$ compared to hydrometeors. Note that the scene investigated is a short period in spring time in the midlatitudes. In other seasons, the a priori covariance will likely look different, especially for the hydrometeors. In winter, for example, snow can reach the ground and there would be a non-zero covariance down to the ground.

There is a rich structure of autocorrelations and correlations between different hydrometeors and over different height levels. The autocorrelation for the different hydrometeor types is mostly positive everywhere, which accounts for the thickness of the cloud layer and the falling precipitation. For SWC and RWC, for example, the correlation in the upper layers is negative. This may be interpreted in terms of the melting layer. Above the melting layer snow exists. It melts below the melting layer forming rain. Therefore precipitating snow in the upper layers will lead to rain in heights below the melting layer.

In the correlation plot also rich structures within the $\mathrm{H}_{2} \mathrm{O}$ related blocks become evident. $\mathrm{H}_{2} \mathrm{O}$ is positively correlated with hydrometeors within the clouds and precipitation regions, since the atmosphere is near saturation there. The negative correlation at lower regions may be due to evaporation in sub-saturated regions. Here, the hydrometeor mass decreases and the $\mathrm{H}_{2} \mathrm{O}$ mass increases. At higher regions above the clouds it may be spurious and stem from the fact that there are only numerical artefacts of very small amounts of hydrometeors in comparison to realistic amounts of $\mathrm{H}_{2} \mathrm{O}$.

The covariance and correlations were calculated on the basis of 1.8 million near-realistic cloudy profiles from the ICON model simulation. With this covariance and correlation from ICON data, we automatically get the crosscorrelations for the different hydrometeor types as well. However, one has to be aware that there are model inherent correlations due to the microphysical parameterization, which can cause some artefacts. Furthermore the choice of thresholds to remove the zero values in the profiles scales the 

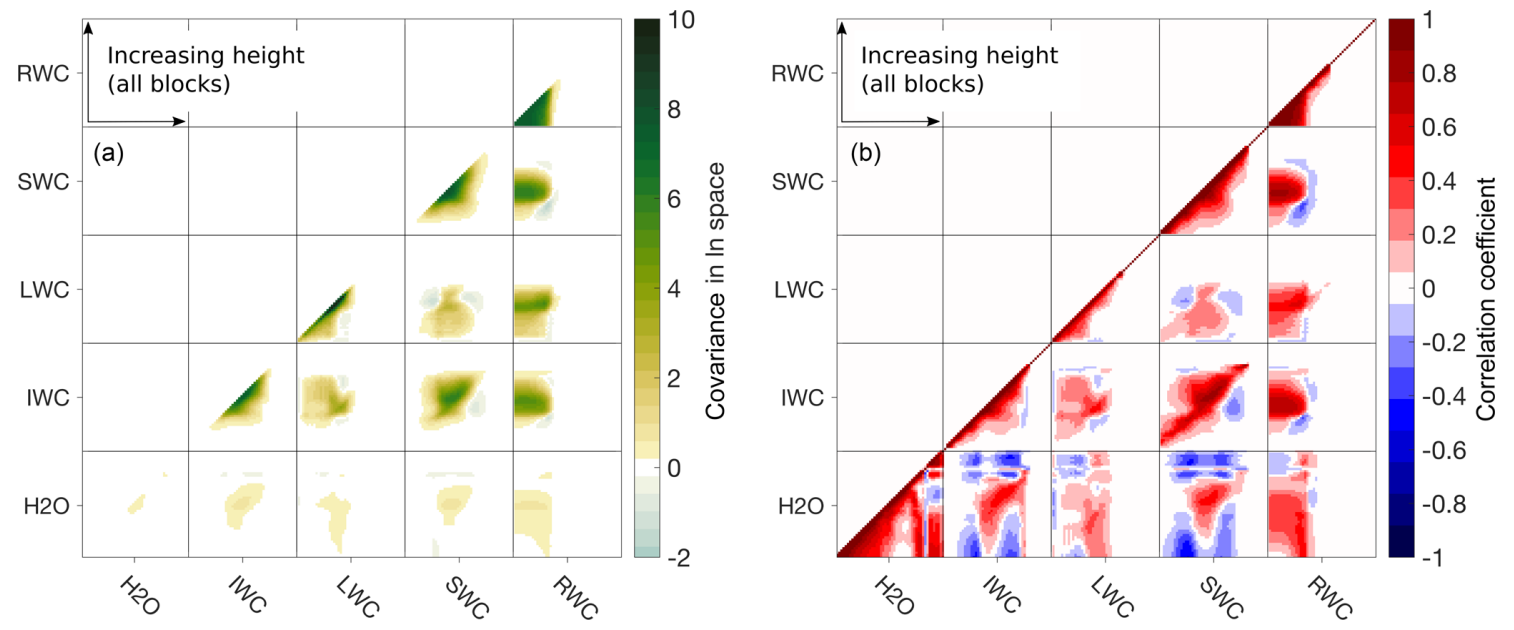

Figure 2. A priori error covariance (a) and the corresponding correlation matrix (b). Only the lower triangle is shown for clarity, since the matrices are symmetric. The block matrices correspond to the (auto-)correlation for one or between two quantities. They have the dimension of $49 \times 49$ height levels each, the height increases within the blocks from left to right and from bottom to top. Note that the variability of $\mathrm{H}_{2} \mathrm{O}$ is so small in comparison to the hydrometeors (in the range of 0 to 1 ) that only little covariance can be seen in the a priori covariance (a) due to the scaling.

covariance and therefore will affect the information content. The terrain following coordinates of ICON cause slightly larger covariances in the lower levels for $\mathrm{H}_{2} \mathrm{O}$ and rain, which are both present near the ground. Idealized covariance matrices might be constructed instead (e.g. Aires et al., 2018), but they have different downsides and also contain many assumptions, especially for the cross-correlation of hydrometeors. We therefore chose the model based a priori covariance matrix to perform the study, keeping in mind the downside that the model introduces some artificial correlations between the hydrometeors.

\section{Setup}

\subsection{Channels}

Radiometer channels as applied on the International Submillimetre Microwave Airborne Radiometer (ISMAR, Fox et al., 2017) and on the Microwave Airborne Radiometer Scanning System (MARSS, McGrath and Hewison, 2001) are used. They both were deployed on a recent flight campaign (Brath et al., 2018) and cover channels from 89.0 up to $664.0 \mathrm{GHz}$. ISMAR will be extended with a channel at $874.4 \mathrm{GHz}$ in near future. They include the AMSU-B channels and the ICI setup, with the exception that the ICI-1, ICI-2 and ICI-3 channels have a slightly different distance from the $\mathrm{H}_{2} \mathrm{O}$ absorption peak at $183.31 \mathrm{GHz}$ (Pica et al., 2012). We will later use the three $183.31 \mathrm{GHz}$ channels from MARSS instead. The setup is further complemented by two channels at 23.8 and $50.1 \mathrm{GHz}$ from the Dual-frequency Extension to In-flight Microwave Observing System (Deimos, Hewison, 1995) to account for lower frequency precipitation channels, which are also part of MWI. The resulting set of channels, their side bands, and the respective instrument they belong to is given in Table 2 .

With this setup it is possible to investigate the principle interdependencies of the information content on different hydrometeors from a set of channels, which is capable of observing liquid and frozen cloud as well as precipitation hydrometeors. However, it is also possible to put a special focus on the upcoming ICI instrument on MetOp-SG, which employs channels from 183 to $664.0 \mathrm{GHz}$ to gain more detailed information about cloud ice, its microphysical properties and perhaps some more profile information than the instruments that are currently deployed in the different satellite missions.

\subsection{Atmospheric profiles}

To facilitate the analysis a mean profile (Fig. 3) from 10000 ICON profiles, which each are amongst the extremes for one specific hydrometeor or the humidity, was calculated. To choose the 10000 profiles, the hydrometeor paths for each hydrometeor type and each atmospheric profile were calculated. To exclude unphysical outliers, which may be produced by the model, profiles with a hydrometeor path larger than the 99th percentile were disregarded. From the remaining profiles we chose $10000 / 7$ largest $\mathrm{H}_{2} \mathrm{O}$ paths, LWPs, IWPs, RWPs, SWPs and the paths for hail and graupel (the "divided by seven" stems from the seven quantities, over which the loop is done). This ensures that a considerable amount of each hydrometeor, except for hail and graupel, which only exist in very small amounts over the whole simulation, is contained in the profile. However, since the 10000 atmospheres are not required to be extreme with regard to (or contain all) hydrometeor types at once, this 
Table 2. Selected set of channels from the instruments MARSS, ISMAR and Deimos. Channels equal or similar to the ones of the MetOp-SG mission (ICI and MWI) are marked in the right column.

\begin{tabular}{lrrll}
\hline $\begin{array}{l}\text { Centre } \\
\text { frequency } \\
{[\mathrm{GHz}]}\end{array}$ & $\begin{array}{r}\text { Side } \\
\text { bands } \\
{[\mathrm{GHz}]}\end{array}$ & $\begin{array}{r}\text { Band- } \\
\text { widths } \\
{[\mathrm{GHz}]}\end{array}$ & $\begin{array}{l}\text { Instrument } \\
\text { METOP-SG }\end{array}$ \\
\hline 23.8 & \pm 0.07 & 0.127 & Deimos & MWI-2 \\
50.1 & \pm 0.08 & 0.082 & Deimos & near MWI-4 \\
89.0 & \pm 1.1 & 0.65 & MARSS & MWI-8 \\
118.75 & \pm 1.1 & 0.4 & ISMAR & near MWI-12 \\
118.75 & \pm 1.5 & 0.4 & ISMAR & near MWI-11 \\
118.75 & \pm 2.1 & 0.8 & ISMAR & near MWI-10 \\
118.75 & \pm 3.0 & 1.0 & ISMAR & near MWI-9 \\
118.75 & \pm 5.0 & 2.0 & ISMAR & \\
157.05 & \pm 2.6 & 2.6 & MARSS & \\
183.31 & \pm 1.0 & 0.45 & MARSS & near ICI-3 \\
183.31 & \pm 3.0 & 1.0 & MARSS & near MWI-17, \\
& & & & near ICI-2 \\
183.31 & \pm 7.0 & 2.0 & MARSS & near ICI-1 \\
243.20 & \pm 2.5 & 3.0 & ISMAR & near MWI-18 \\
& & & & ICI-4 \\
325.15 & \pm 1.5 & 1.6 & ISMAR & ICI-7 \\
325.15 & \pm 3.5 & 2.4 & ISMAR & ICI-6 \\
325.15 & \pm 9.5 & 3.0 & ISMAR & ICI-5 \\
424.70 & \pm 1.0 & 0.4 & ISMAR & \\
424.70 & \pm 1.5 & 0.6 & ISMAR & \\
424.70 & \pm 4.0 & 1.0 & ISMAR & \\
448.0 & \pm 1.4 & 1.2 & ISMAR & ICI-10 \\
448.0 & \pm 3.0 & 2.0 & ISMAR & ICI-9 \\
448.0 & \pm 7.2 & 3.0 & ISMAR & ICI-8 \\
664.0 & \pm 4.2 & 3.0 & ISMAR & ICI-11 \\
874.4 & \pm 6.0 & 3.0 & ISMAR & \\
\hline & & & & \\
\hline
\end{tabular}

gives us 10000 cloudy profiles and on average a mean profile which is not extreme for any hydrometeor and which is comparably smooth. The mean profile that follows from these choices contains realistic amounts of hydrometeor masses. Cloud and precipitation are located in physically reasonable height ranges. However, it has to be kept in mind that this may lead to an unlikely combination of hydrometeors, such as LWC and SWC being present in the same atmospheric column. Therefore in Sect. 6.4, we will also show results from a set of 90 individual cloudy atmospheric columns drawn directly from the selected ICON simulation to consolidate the results from the idealized atmosphere.

This mean profile is used as a "base profile" containing all hydrometeors. From this base profile atmospheres with different combinations of cloud hydrometeors are constructed by taking out or putting in specific hydrometeors. A similar approach has been used by Guerbette et al. (2016), who progressively put in cloud hydrometeors to quantify their respective influence on the brightness temperature in the $183 \mathrm{GHz}$ channel of the humidity sounder SAPHIR on Megha-Tropiques. This study investigates if the information about one hydrometeor type depends on the presence of another. For example, we can have an atmosphere which contains only LWC, only IWC or one which contains the two hydrometeor types IWC and RWC. All in all 16 combinations including clear sky are possible. We are aware that not all combinations are physically possible and realistic, such as an atmosphere only containing SWC, but we want to understand how the measurement of one hydrometeor is in principle influenced by the others. Therefore all mathematically possible combinations are regarded.

The different atmospheres are denoted by an $a_{X}$, where $X$ contains the composition of the atmosphere. LWC is denoted by L, IWC by I, RWC by R and SWC by S. For example, the atmosphere containing IWC and LWC is called $a_{\mathrm{IL}}$. The clear sky case ("Vapour") is called $a_{\mathrm{V}}$. Note that $\mathrm{H}_{2} \mathrm{O}$ is present in all of the atmospheres, even though it is not explicitly included in $X$ in case hydrometeors are present. An overview over the atmospheric compositions is given in Table 3.

\section{Results}

\subsection{Brightness temperature spectra}

The brightness temperatures for the different atmospheric compositions are shown in Fig. 4 for an emissivity of $\epsilon=0.6$. The brightness temperature spectra differ by up to $80 \mathrm{~K}$, depending on the atmospheric composition and the measurement channel. In the window channels, the spread in the spectra is particularly large, while in the sounding channels near the absorption peaks the spread is smaller. For channels close to absorption line centres the spectra almost lie on top of each other because here the atmosphere is opaque due to $\mathrm{H}_{2} \mathrm{O}$ absorption.

Some of the different compositions such as $a_{\mathrm{L}}$ and $a_{\mathrm{LR}}$ or $a_{\mathrm{IS}}$ and $a_{\mathrm{IRS}}$, have almost the same spectra except for differences in the window channels below $118.75 \mathrm{GHz}$. This implies that some hydrometeors are invisible to channels higher than that.

The brightness temperature is a result of the complex interaction of the radiation with the atmosphere. First, there is extinction, i.e. absorption, mainly caused by $\mathrm{H}_{2} \mathrm{O}$ and by the liquid hydrometeors and scattering, mainly caused by the frozen hydrometeors. Extinction determines how far down a certain channel can see. This also determines the sensitivity of a channel to an atmospheric component to some degree. If the channels do not reach down to levels where, for example, rain exists, naturally it is not sensitive to rain in that case. The whole hydrometeor path of a certain hydrometeor, which is in the pathway of the channel, contributes to the signal. It depends on the respective path of the hydrometeor and the sensitivity of the channel to that hydrometeor how big the contribution is. If we look at one particular hydrometeor, the combined signals of all other atmospheric components provide the radiative background for the signal of that particular 

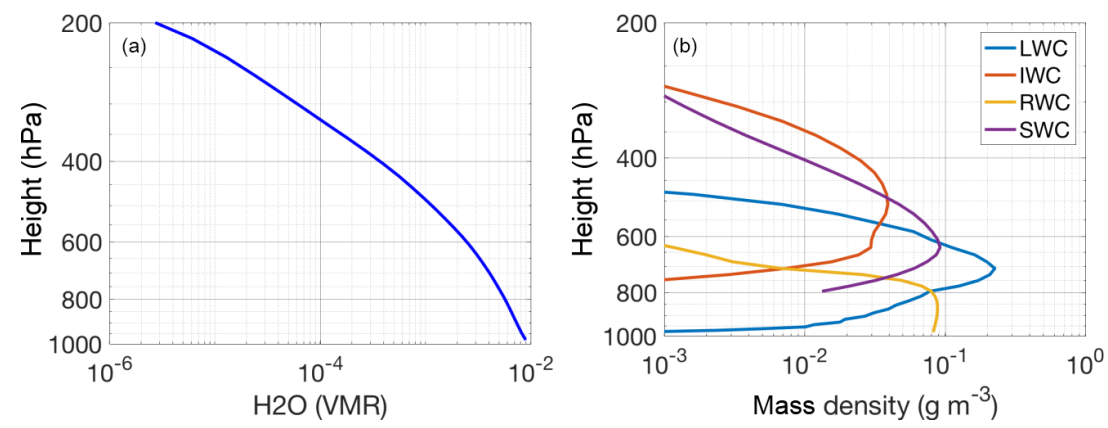

Figure 3. Idealized atmospheric base profile. $\mathrm{H}_{2} \mathrm{O}$ volume mixing ratio (VMR, a) and particle mass densities (b) for LWC, IWC, RWC and SWC. The respective paths are $\mathrm{LWP}=0.45 \mathrm{~kg} \mathrm{~m}^{-2}, \mathrm{IWP}=0.17 \mathrm{~kg} \mathrm{~m}^{-2}, \mathrm{RWP}=0.18 \mathrm{~kg} \mathrm{~m}^{-2}, \mathrm{SWP}=0.30 \mathrm{~kg} \mathrm{~m}^{-2}$ and $\mathrm{H}_{2} \mathrm{O}$ path $=25.00 \mathrm{~kg} \mathrm{~m}^{-2}$.

Table 3. Atmospheric compositions used in the analysis of the dependency of the information content on the atmospheric composition.

\begin{tabular}{|c|c|c|c|c|c|c|c|c|c|c|c|c|c|c|c|c|c|}
\hline & & \multicolumn{16}{|c|}{ Atmosphere } \\
\hline & & $a_{\mathrm{V}}$ & $a_{\mathrm{L}}$ & $a_{\mathrm{R}}$ & $a_{\mathrm{I}}$ & $a_{\mathrm{S}}$ & $a_{\mathrm{LR}}$ & $a_{\mathrm{LI}}$ & $a_{\mathrm{LS}}$ & $a_{\mathrm{RI}}$ & $a_{\mathrm{RS}}$ & $a_{\mathrm{IS}}$ & $a_{\text {LRI }}$ & $a_{\mathrm{LRS}}$ & $a_{\text {LIS }}$ & $a_{\mathrm{RIS}}$ & $a_{\text {LRIS }}$ \\
\hline \multirow{5}{*}{ 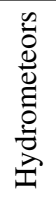 } & Vapour & $X$ & $X$ & $X$ & $X$ & $X$ & $X$ & $X$ & $X$ & $\mathrm{X}$ & $\mathrm{X}$ & $X$ & $X$ & $\mathrm{X}$ & $X$ & $\mathrm{X}$ & $\mathrm{X}$ \\
\hline & LWC & & $X$ & & & & $\mathrm{X}$ & $X$ & $X$ & & & & $\mathrm{X}$ & $\mathrm{X}$ & $X$ & & $\mathrm{X}$ \\
\hline & RWC & & & $X$ & & & $\mathrm{X}$ & & & $X$ & $X$ & & $X$ & $\mathrm{X}$ & & $X$ & $\mathrm{X}$ \\
\hline & IWC & & & & $X$ & & & $X$ & & $X$ & & $X$ & $X$ & & $X$ & $X$ & $\mathrm{X}$ \\
\hline & SWC & & & & & $X$ & & & $\mathrm{X}$ & & $X$ & $X$ & & $\mathrm{X}$ & $X$ & $X$ & $\mathrm{X}$ \\
\hline
\end{tabular}

hydrometeor. This may lead to a "shielding" of hydrometeors in the lower levels, because the water vapour path or hydrometeor path above those hydrometeors is so large that the atmosphere is entirely opaque for a channel. The signal from a certain hydrometeor can also be masked by other hydrometeors, that create a radiative background through absorption or scattering, which is similar to the radiative signal of the hydrometeor in question. In the following we investigate this further. We will have a closer look at the sensitivities of the brightness temperature to changes in the hydrometeor mass, namely the Jacobians $J$, in the absence and presence of other hydrometeors.

\subsection{Cloudy sky Jacobians}

We first look at the Jacobians for $\mathrm{H}_{2} \mathrm{O}$ for the clear sky case $a_{\mathrm{V}}$ and the all-hydrometeors case $a_{\text {ILRS }}$ are analysed (Fig. 5). $\mathrm{H}_{2} \mathrm{O}$ has the advantage that its profile is smooth and continuous, contrary to the hydrometeor Jacobians which per definition of the relative perturbation only exist where the cloud hydrometeors reside and which decrease to zero at the cloud edge with a steep gradient. With the chosen surface emissivity of $\epsilon=0.6$, for $a_{\mathrm{V}}, \mathrm{H}_{2} \mathrm{O}$ gives a warming signal from the lower atmosphere ( $>500 \mathrm{hPa}$ ) at channels from 157.05 GHz downward and at $243.2 \mathrm{GHz}$. For channels from $183.31 \mathrm{GHz}$ upward it gives a small cooling signal at higher levels $(<650 \mathrm{hPa})$. Hereby "warming signal" ("cooling signal") means that an increase of the amount of vapour or hy- drometeor content leads to a warming (cooling) of the resulting brightness temperature at the top of the atmosphere. This is mainly due to the fact that the Jacobians for the sounding channels higher than $183 \mathrm{GHz}$ peak higher up in the atmosphere than the Jacobians of the lower channels and that these higher regions are very cold compared to the ground.

This picture changes dramatically in the presence of all considered cloud hydrometeors ( $a_{\text {ILRS }}$ ). Except for the most central frequencies of the sounding channels at 183.31 and $448.0 \mathrm{GHz}$ the $\mathrm{H}_{2} \mathrm{O}$ signal in this case is entirely positive. The positive signal in between the channels at 157.05 and $23.8 \mathrm{GHz}$ decreases to almost zero. The sensitivity of the measured brightness temperature to changes in $\mathrm{H}_{2} \mathrm{O}$ is highly dependent on the presence of clouds.

The $\mathrm{H}_{2} \mathrm{O}$ example illustrates the general principle of these interactions well. If the radiative background is cold, then the presence of a scattering or absorbing species tends to increase the brightness temperature. Conversely, if the background is warm, then the species tends to reduce the brightness temperature. For $\mathrm{H}_{2} \mathrm{O}$ at high frequencies, the presence of frozen hydrometeors in the upper troposphere, which have a cooling signal due to scattering, turns the scene from a warm background case to a cold background case.

Figure 6 illustrates Jacobians from atmospheres with one single liquid hydrometeor type each, i.e. $a_{\mathrm{L}}$ and $a_{\mathrm{R}}$ for both, LWC or RWC, along with the corresponding $\mathrm{H}_{2} \mathrm{O}$ Jacobians. As relative perturbation for the calculation of the Jacobians were used, (Eq. 5), the cloud Jacobians only exist at those 


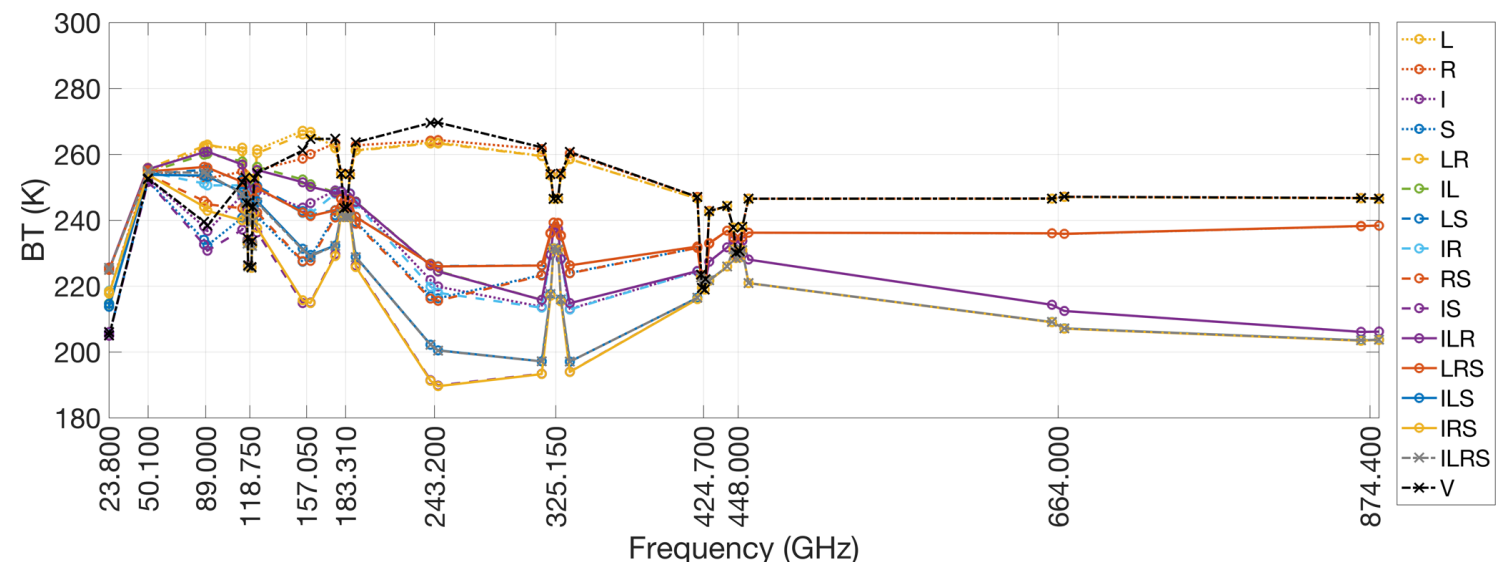

Figure 4. Brightness temperature spectrum for $\epsilon=0.6$ for the 16 combinations of the base profile. The legend corresponds to the composition suffixes $\mathrm{X}$ defined in Table 3. The labels on the abscissa are the centre frequencies of the channels. The curve labelled " $\mathrm{V}$ " is for $\mathrm{H}_{2} \mathrm{O}$ only, without any hydrometeors. Although not mentioned in the legend, vapour is also present in all the other calculations.
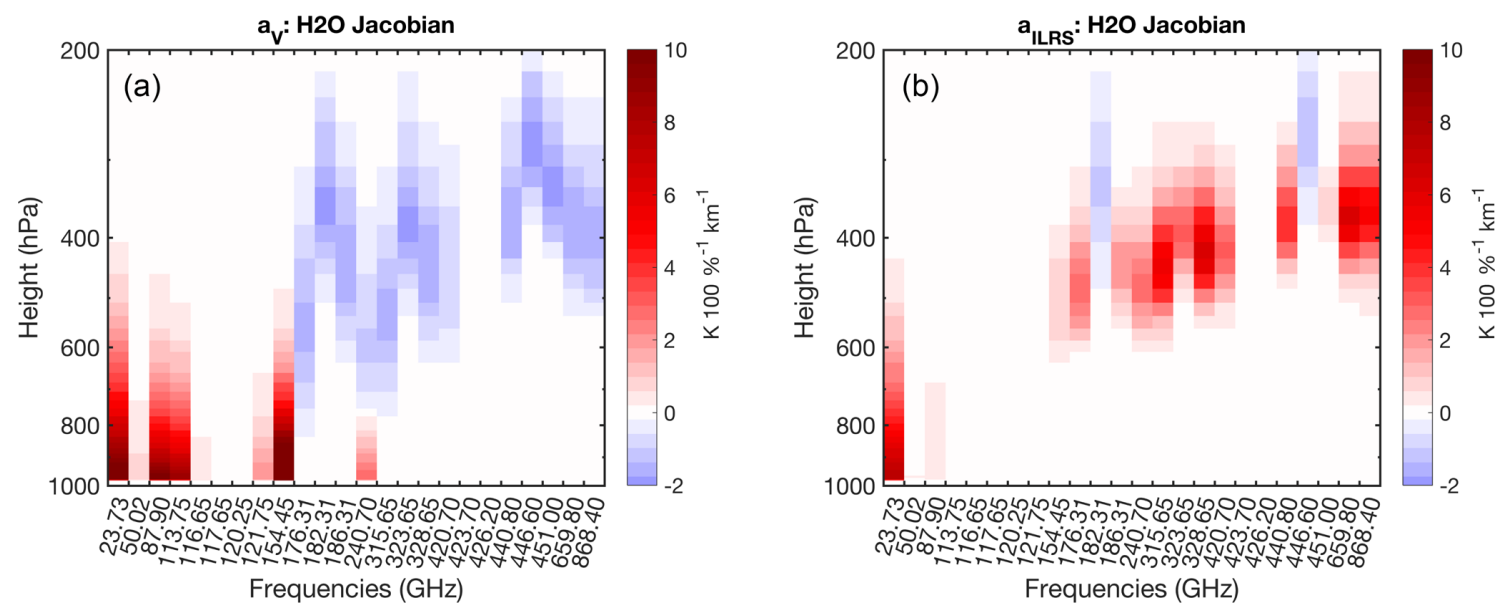

Figure 5. $\mathrm{H}_{2} \mathrm{O}$ Jacobians for the clear sky case $a_{\mathrm{V}}$ (a) and for the all-hydrometeor case $a_{\mathrm{ILRS}}$ (b) for an emissivity $\epsilon=0.6$. Averages of the sidebands are shown, the labels on the abscissa denote the left sideband of the channel.

heights where LWC or RWC exist (cp. Fig. 3). These heights are indicated in the figures for two different thresholds for the respective mass densities. Mainly the channels below $325.15 \mathrm{GHz}$ (LWC) respectively $243.2 \mathrm{GHz}$ (RWC) are sensitive to the liquid hydrometeors. The window channels at 23.8, 50.1 and $89.0 \mathrm{GHz}$ give a warming signal at all heights, the outermost channel at $118.75 \mathrm{GHz}$ (and $157.05 \mathrm{GHz}$ for RWC) have a warming signal at lower levels and a cooling signal at upper levels. Note that a higher surface emissivity, i.e. a radiatively warmer surface, reduces the warming signal from LWC and RWC in the window channels, since the surface provides a warmer background in that case (not shown). The Jacobians for $\mathrm{H}_{2} \mathrm{O}$ change in the presence of LWC or RWC. Apart from $23.8 \mathrm{GHz}$ the warming signal in the lower channels is considerably reduced compared to the warming signal from $\mathrm{H}_{2} \mathrm{O}$ alone.
The frozen hydrometeor types IWC and SWC generally give a cooling signal (Fig. 7) as they mainly act as scatterers rather than absorbers in the selected channel range. Also, they exist at low ambient temperatures, and even their emission would cause a cooling signal. The upper channels above $157.05 \mathrm{GHz}$ are sensitive to these hydrometeor types. For SWC a considerable signal also comes from the channels at $50.1,89.0$ and the outermost $118.75 \mathrm{GHz}$ channel. The highest channels at 664.0 and $874.4 \mathrm{GHz}$ are more sensitive to IWC than to SWC because the scattering efficiency in these two channels is larger for the smaller ice hydrometeors than for the larger snow hydrometeors.

The corresponding $\mathrm{H}_{2} \mathrm{O}$ Jacobians are considerably changed at channels above $157.05 \mathrm{GHz}$. The cooling signal from the clear sky $\mathrm{H}_{2} \mathrm{O}$ Jacobians (Fig. 5) is turned into a warming signal except for the sounding channels closest to the absorption lines. This is in accordance with the findings 

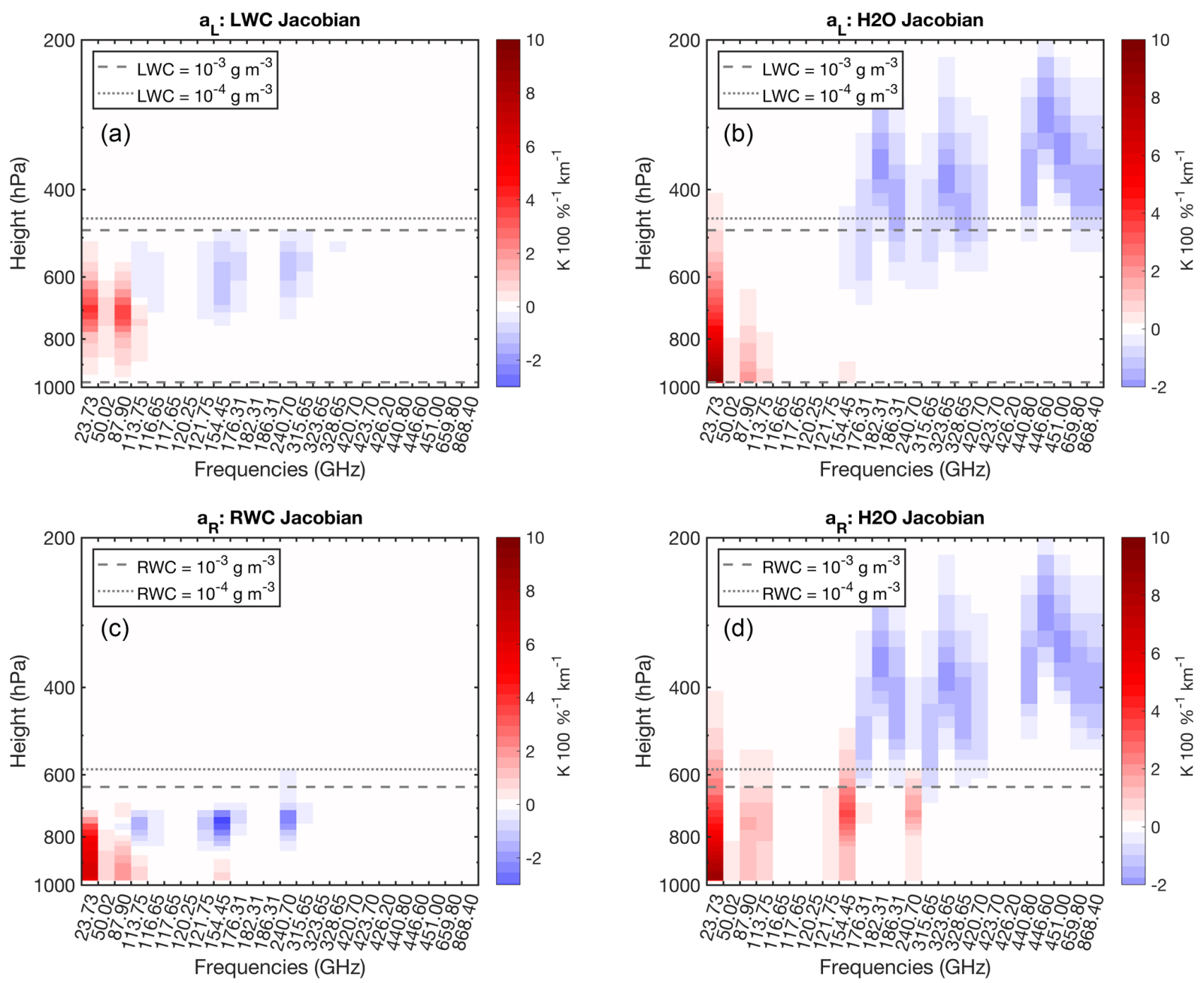

Figure 6. LWC (a) and $\mathrm{H}_{2} \mathrm{O}$ (b) Jacobians for $a_{\mathrm{L}}$, and RWC (c) and $\mathrm{H}_{2} \mathrm{O}$ (d) Jacobians for $a_{\mathrm{R}}(\epsilon=0.6)$. The dashed (dotted) grey line denotes the height in which the mass content of the respective hydrometeor is nearest $10^{-3} \mathrm{~g} \mathrm{~m}^{-3}\left(10^{-4} \mathrm{~g} \mathrm{~m}^{-3}\right)$. Note that both hydrometeor types reach far down to the ground such that the lower edges are not always visible in the plots.

of Guerbette et al. (2016) who found such a change of sign in the lowest-peaking SAPHIR channels near $183 \mathrm{GHz}$ in the presence of high concentrations of snow above $500 \mathrm{hPa}$.

Next, we will go deeper into the interdependencies of the hydrometeor Jacobians. For this purpose, the view chosen in the previous figures is reduced, and only the Jacobians for the channels at 89.0 and $243.2 \mathrm{GHz}$ are shown as line plots (Figs. 8 and 9). In these channels we expect to get a signal from all cloud hydrometeors, while $89.0 \mathrm{GHz}$ is more sensitive to the liquid hydrometeors and $243.2 \mathrm{GHz}$ is more sensitive to the frozen hydrometeors. The Jacobians are shown for each cloud hydrometeor type for the cases where only that specific type is present, one other hydrometeor type is present, or all types are present in a combined plot. For the example of cloud ice these are IWC Jacobians for the cases $a_{\mathrm{I}}, a_{\mathrm{IL}}, a_{\mathrm{IS}}, a_{\mathrm{IR}}$, and $a_{\mathrm{ILRS}}$.

For the LWC Jacobians (Fig. 8, top row), the lines group in two sets in both channels. In the $89.0 \mathrm{GHz}$ channel, the signal is reduced in the presence of RWC in the lower levels. The presence of frozen hydrometeors does not alter the signal much. The pairs not including RWC, $a_{\mathrm{IL}}$ and $a_{\mathrm{LS}}$, almost give the same Jacobian as $a_{\mathrm{L}}$, while both $a_{\mathrm{LR}}$ and the all-hydrometeors case $a_{\text {ILRS }}$ have a smaller peak and are very close up to about $700 \mathrm{hPa}$. Above that level, SWC has a greater influence. The Jacobian for $a_{\mathrm{LS}}$ deviates from the one of $a_{\mathrm{L}}$ and the all-hydrometeor case $a_{\mathrm{ILRS}}$ approaches the curve for the case $a_{\mathrm{LS}}$. The change of behaviour near $700 \mathrm{hPa}$ is due to the height ranges where SWC or RWC occur, respectively. Near $700 \mathrm{hPa}$, the melting layer of the idealized atmosphere is located (see Fig. 3).

The $243.2 \mathrm{GHz}$ channel has its largest sensitivity for the detection of RWC higher up in the atmosphere than the channel at $89 \mathrm{GHz}$ and therefore does not exhibit such a transition. The two cases $a_{\mathrm{L}}$ and $a_{\mathrm{LR}}$ which only contain liquid hydrometeors have negative LWC Jacobians, while the presence of any frozen hydrometeors results in positive LWC Ja- 

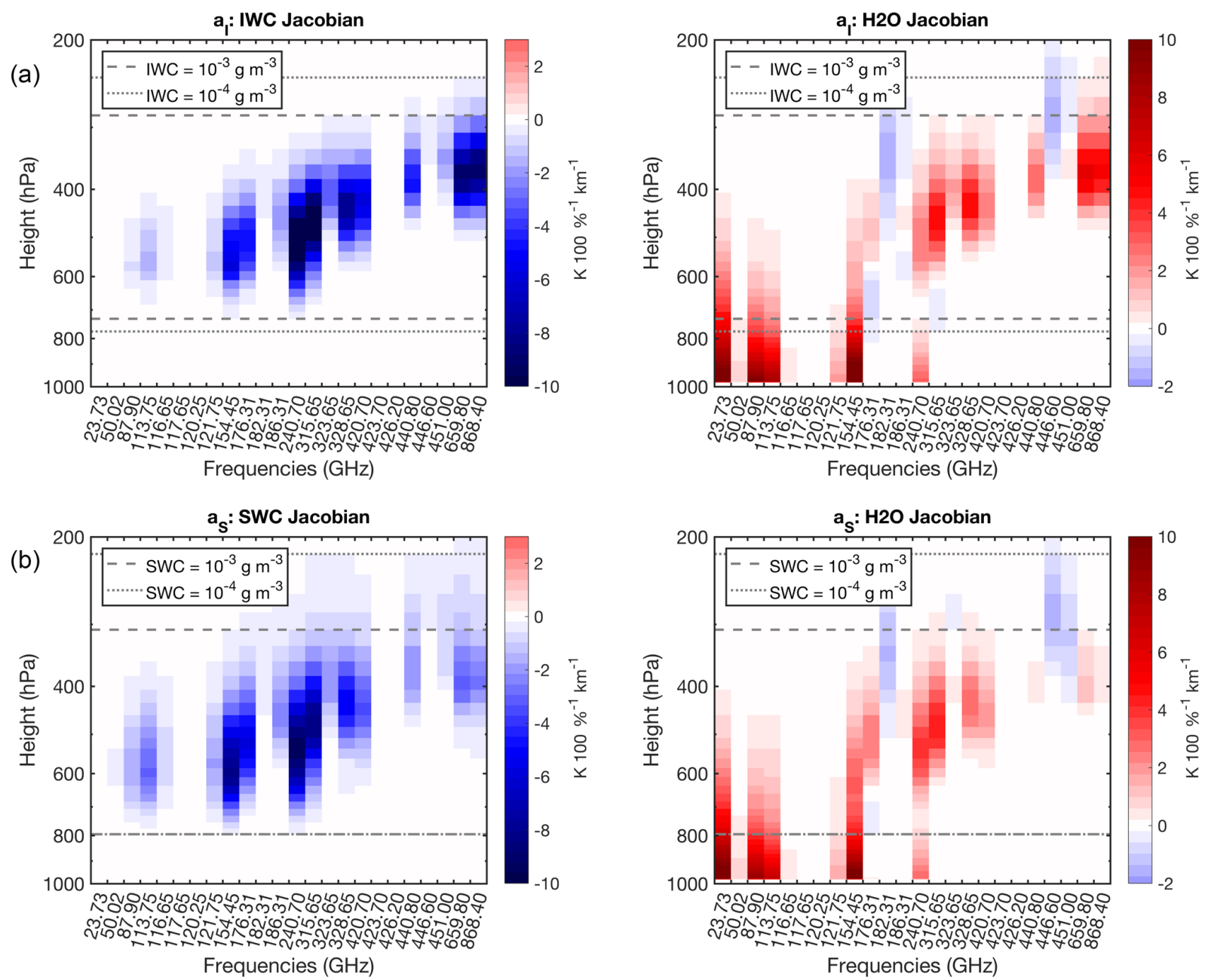

Figure 7. Same as Fig. 6 but for IWC (a) and SWC (b).

cobians. The largest signal comes from the all-hydrometeors case $a_{\text {ILRS }}$, the smallest positive one from the combination of LWC with IWC, i.e. $a_{\mathrm{IL}}$.

This again can be understood if we think of the other cloud hydrometeors as contributors to the mixture of signals from all heights and hydrometeors, which result in the respective brightness temperature. The paths of the other cloud hydrometeor types, the surface and the $\mathrm{H}_{2} \mathrm{O}$ create a radiative background for the hydrometeor type in question. At $89.0 \mathrm{GHz}$, the presence of RWC already increases the brightness temperature, therefore the emission from LWC only adds a smaller positive increment compared to an atmosphere where only LWC is present. At $243.2 \mathrm{GHz}$, the scattering by frozen particles decreases the measured brightness temperature such that the emission by LWC adds a positive increment instead of a negative one if no IWC or SWC is present. These effects are not linear and can not just be added up.

For RWC (Fig. 8, bottom row), in the $89.0 \mathrm{GHz}$ channel we also find a grouping of the Jacobians similar to LWC. For RWC the sign of the signal depends on the height. The lower levels cause a warmer background, such that the higher levels' contribution is negative compared to it. In the $243.2 \mathrm{GHz}$ channel, the signal from rain is negative with the exception of a small positive contribution near the ground. The addition of any of the other hydrometeor types decreases the amplitude of the Jacobian. Each hydrometeor type alone, LWC, IWC and SWC, gives a cooling signal and therefore causes a colder background in the mixture compared to the case where only RWC is present.

Figure 9 shows the corresponding figures for the frozen hydrometeors IWC and SWC for the two channels. Since the main interaction of the frozen particles with the radiation is scattering, the signal is robustly negative. In the $89.0 \mathrm{GHz}$ channel, the IWC Jacobians for $a_{\mathrm{I}}$ and $a_{\mathrm{IS}}$ as well as the SWC Jacobians for $a_{\mathrm{S}}$ and $a_{\mathrm{IS}}$ are very similar. IWC and SWC only marginally influence each other in that channel. The addition of liquid hydrometeors below the frozen ones leads to a stronger signal for IWC and SWC, because the liquid hydrometeors provide a warmer background for the frozen hydrometeors. In the $243.2 \mathrm{GHz}$ channel, the picture 

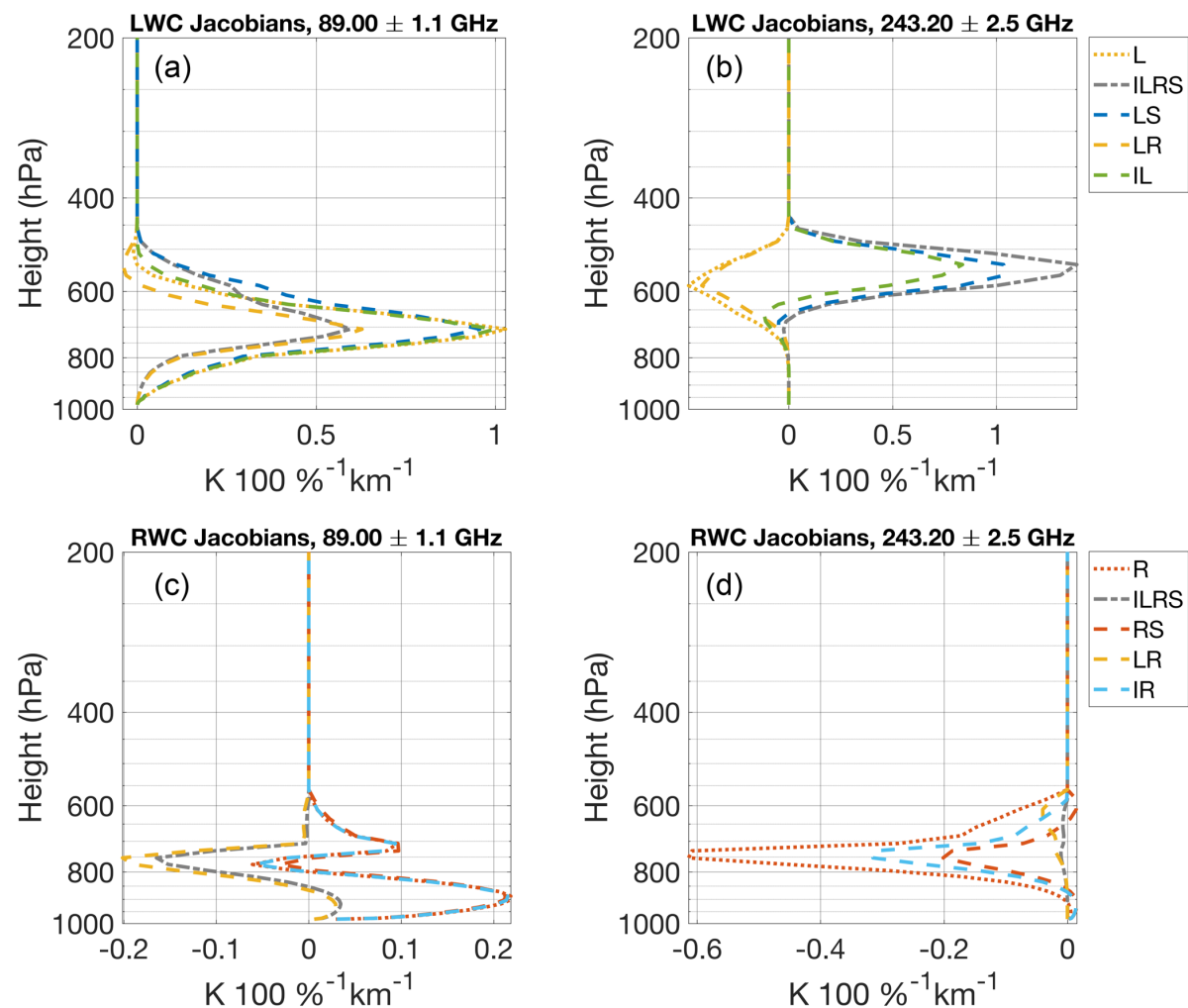

Figure 8. LWC (a) and RWC (b) Jacobians for the $89.0 \mathrm{GHz}$ (a, c) and the $243.2 \mathrm{GHz}$ (b, d) channel $(\epsilon=0.6)$. Shown are atmospheres

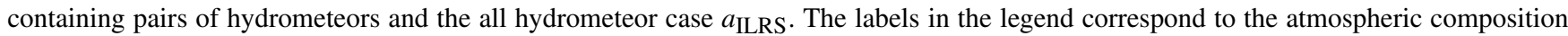
suffix X. Note different values on the abcissa in the different plots.

is almost the same. In this channel, however, the signals from the frozen hydrometeors are much stronger, and the combination of IWC and SWC results in a considerably stronger cooling signal for both cloud hydrometeor types. Therefore the Jacobians for the all-hydrometeors case $a_{\text {ILRS }}$ lie between $a_{\mathrm{IS}}$ and the other shown cases.

\subsection{Information content}

The amount of the information gained from the observation depends on the composition of the atmosphere. Figure 10 and Table 4 summarize $\triangle \mathrm{DOF}$ for the 16 different atmospheric compositions, observed with the full set of channels and observed with the ICI channels. The analysis for particle mean mass $(\bar{m})$ Jacobians was not shown in the previous sections, but we include the values for their information content in this section to show the potential of new sensors observing at frequencies of $183 \mathrm{GHz}$ and higher to observe microphysical properties of the particles.

The main focus is on the detection of frozen hydrometeors, but in the following also the information content for liquid hydrometeors is included in the discussion. Liquid water retrievals at lower microwave channels are an established technique. For example a higher number of frequencies within the sounding regions between 50 and $57 \mathrm{GHz}$, which could be used in combination with the $118.75 \mathrm{GHz}$ channels would be able to retrieve liquid cloud and precipitation, as was shown by Bauer and Mugnai (2003). We lack channels in the region between 50 and $57 \mathrm{GHz}$, therefore in this analysis, we do not expect to have a great ability to detect liquid hydrometeors. We set our main focus on frozen hydrometeors. Nevertheless they will be discussed along with the information content on frozen hydrometeors and be treated as a side parameter for the detection of the frozen hydrometeors.

For the full set of channels, the total information content reaches up to values as high as 12.15 for $a_{\text {ILRS }}$ and is lowest for the clear sky case $a_{\mathrm{V}}$ with 3.44 (Table 4).

Naturally, the more complex the atmosphere is, the higher the overall possible total information content is. The initial degrees of freedom for these cases are more numerous and a greater portion of the channels can be used to reduce them (Fig. 10). The major part of the information comes from the frozen hydrometeors. IWC gains most information for both the mass density ( 3.10 on average) and the particle mean masses (3.28 on average). The information content for the mean mass of IWC is greater than the one for the mass density of IWC. It is necessary to keep in mind the specific choice of the a priori assumptions. The information content is in principle high for IWC. The proportion between the information content for the mass density and the mean mass of 

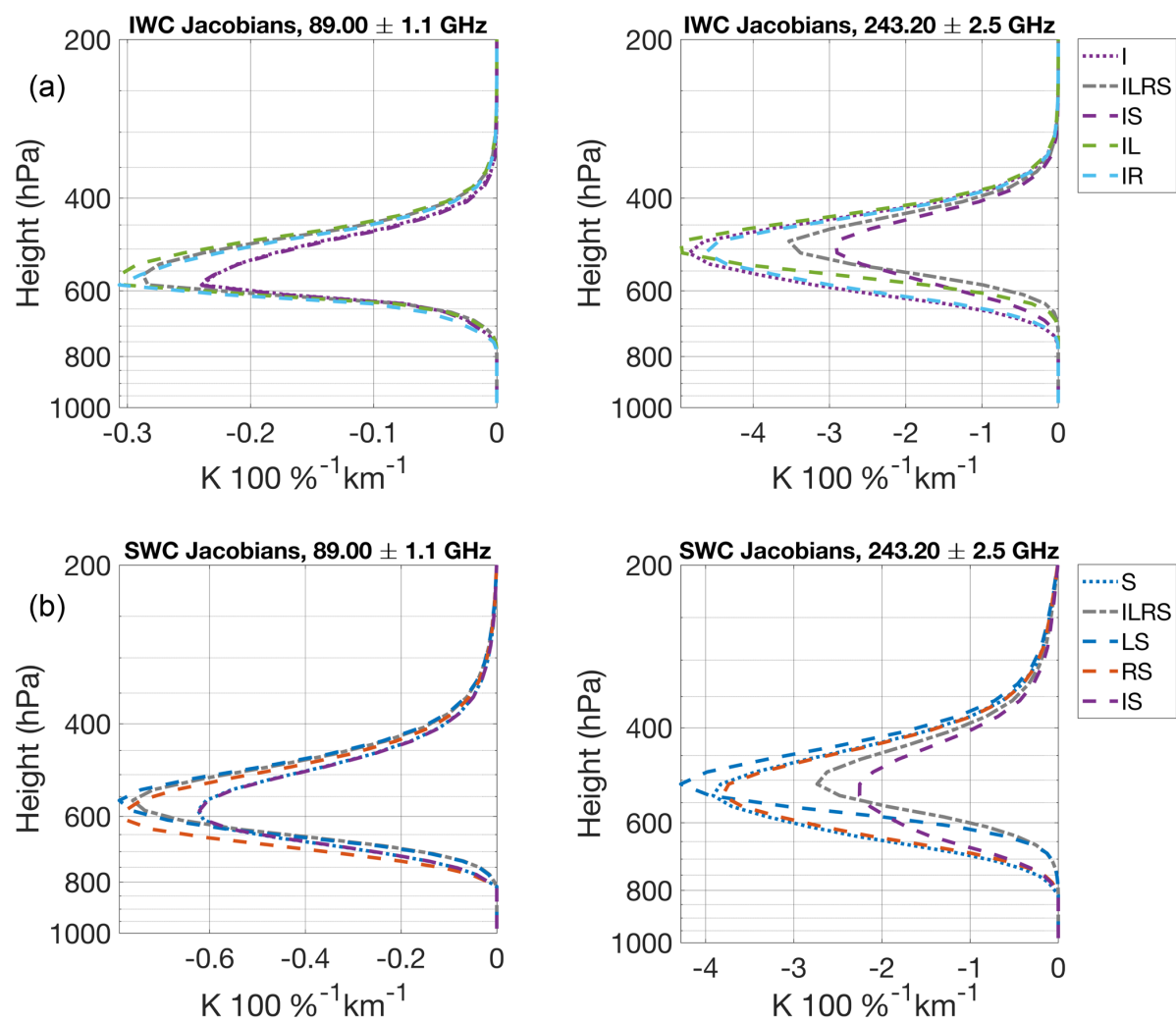

Figure 9. Same as Fig. 8, but for IWC (a) and SWC (b).

Table 4. Information content $\triangle \mathrm{DOF}$. Shown are mean of the total $\triangle \mathrm{DOF}$ over the 16 different compositions, minimum and maximum of the total $\triangle \mathrm{DOF}$, and the mean, minimum and maximum $\triangle \mathrm{DOF}$ for hydrometeor mass densities and the corresponding particle mean masses $(\bar{m})$.

\begin{tabular}{llll|lll}
\hline & \multicolumn{3}{c|}{ All channels } & \multicolumn{3}{c}{ ICI channels } \\
\cline { 2 - 7 } & Min & Mean & Max & Min & Mean & Max \\
\hline Total & 3.44 & 9.14 & 12.15 & 2.65 & 6.19 & 8.20 \\
$\mathrm{H}_{2} \mathrm{O}$ & 1.21 & 1.96 & 3.44 & 0.92 & 1.40 & 2.65 \\
IWC & 2.58 & 3.10 & 3.65 & 2.29 & 2.76 & 3.32 \\
SWC & 1.58 & 2.57 & 3.56 & 1.23 & 2.27 & 3.44 \\
IWC $\bar{m}$ & 2.78 & 3.28 & 3.88 & 2.28 & 2.70 & 3.20 \\
SWC $\bar{m}$ & 1.17 & 1.73 & 2.42 & 0.87 & 1.31 & 1.77 \\
LWC & 1.41 & 1.69 & 2.20 & 0.16 & 0.42 & 1.00 \\
RWC & 0.72 & 1.08 & 1.89 & $1.8 \times 10^{-3}$ & 0.13 & 0.94 \\
LWC $\bar{m}$ & $0.5 \times 10^{-3}$ & $0.8 \times 10^{-3}$ & $1.3 \times 10^{-3}$ & $0.1 \times 10^{-3}$ & $1.8 \times 10^{-3}$ & $8.2 \times 10^{-3}$ \\
RWC $\bar{m}$ & 0.62 & 0.91 & 1.30 & $0.1 \times 10^{-3}$ & $0.5 \times 10^{-3}$ & $1.6 \times 10^{-3}$ \\
\hline
\end{tabular}

IWC may depend on the choice of the thresholds for the mass density and the mean mass used to calculate the error covariance in ln-space (see Sect. 4.2 and discussion at the end of this section).

SWC gains an information content of 2.57 on average. The mean mass of snow gains 1.73 on average. IWC and SWC compete for the information. If both are included, their information contents both decrease. The decrease is stronger for SWC in the presence of IWC than for IWC in the presence of SWC. This mirrors the behaviour of the Jacobians discussed above. If both frozen hydrometeor types are present, the absolute values of the Jacobians decrease. The spread of the information content for the different atmospheric compositions is slightly higher for SWC, but the minimum information content is high for both, 2.58 for IWC and 1.58 for SWC. The outer channels of the $118 \mathrm{GHz}$ line, the window channels below, and the channel at $157 \mathrm{GHz}$ add a considerable amount of information for LWC (1.69 on average) and 
some for RWC (1.08). For $\mathrm{H}_{2} \mathrm{O}$ under clear sky conditions, a maximum $\triangle \mathrm{DOF}$ of 3.44 is gained, which decreases in the presence of clouds. Once hydrometeors are present in the atmospheric column, the information content for $\mathrm{H}_{2} \mathrm{O}$ is considerably reduced down to 1.21 for the case $a_{\text {ILRS }}$.

The overall picture is the same for both land and ocean, with only slight changes in the ranking of the total information content according to the total $\triangle \mathrm{DOF}$ (not shown). For the higher land emissivities, the cases $a_{\mathrm{ILRS}}, a_{\mathrm{IRS}}$ are swapped. However, their information contents have very similar values in both cases and a small change in the information content easily leads to a slightly different ranking of the atmospheres.

Now the focus is set on ICI, which is designed to detect frozen hydrometeors. The set of channels is reduced to the eleven channels which correspond to this instrument (see Table 2). Naturally, the resulting total mean $\triangle \mathrm{DOF}$ of 6.19 is smaller than before because the number of channels is smaller. This reduction is mostly at the cost of information about the liquid hydrometeors, not the frozen hydrometeors, because the channels below $183 \mathrm{GHz}$ are missing entirely in this case. For IWC the mean information content is only slightly reduced to 2.76 , and for SWC to 2.27 . For the particle mean masses, $\triangle \mathrm{DOF}$ for IWC $\bar{m}$ is reduced to 2.70 and the one for SWC $\bar{m}$ is slightly reduced to 1.31 (Table 4). The information content for liquid hydrometeors is considerably reduced to 0.42 for $\mathrm{LWC}$ and to 0.13 for RWC.

In the ranking according to the total $\triangle \mathrm{DOF}$ (Fig. 10) the atmospheres nicely separate into three groups. The atmospheres containing IWC build the group with highest total $\triangle \mathrm{DOF}$, those containing SWC but no IWC rank second. As before, the four atmospheres with the least information content are those without any frozen hydrometeors. Also information about the microphysical properties of the frozen hydrometeors is gained, although it is reduced compared to the full set of channels. For the purpose of ICI it is no disadvantage to leave out the lower channels. ICI's focus is on the detection of cloud ice and its ability to observe it on the global scale with a large spatial coverage seems to be unprecedentedly high.

We are aware that the results discussed in this section depend on the definition of the a priori covariance error. They especially depend on the choice of the lower threshold for the calculation of the covariance in ln space. If a very large threshold is assumed, the information content will be significantly diminished because there is only little variance left. For a very small numerical threshold, the variance will be large, and we will gain too much information. The dependence of the mean information content on the chosen threshold is shown in Fig. 11 for all hydrometeors for both mass density and mean mass. For cloud ice and snow, also the range between minimum and maximum $\triangle \mathrm{DOF}$ is shown. The mean information content for IWC and SWC decreases from 4.7 down to about 1.5 for thresholds from $10^{-16} \mathrm{~kg} \mathrm{~m}^{-3}$ to $10^{-5} \mathrm{~kg} \mathrm{~m}^{-3}$. The mean information content for IWC $\bar{m}$ and SWC $\bar{m}$ increases by 1.6 or 0.6 , respectively. The dependence of the mean information contents for the liquid hydrometeor mass density and mean masses is weaker. The spread of the minimum and maximum for SWC shows little dependence on the threshold for the mass densities. For IWC, the spread decreases for the mass density but increases for the mean masses. The threshold is only varied for the mass densities, but not for the mean masses. The dependence of the information content for the mean masses is due to the fact that a combined analysis of all variables is performed. Furthermore, the cross correlations between mass densities and mean mass will cause a change of the information content of the mean masses.

For this analysis, thresholds were chosen, which are as physically based as possible (see Sect. 4.2). In particular, we use $10^{-7} \mathrm{~kg} \mathrm{~kg}^{-1}$ for the mass densities. Since this study is based on a spring time case from the mid-latitudes, the variance is likely smaller than one would expect if a whole year was taken into account.

\subsection{Realistic atmospheric profiles}

So far only one single, smooth idealized cloudy profile was analysed. To consolidate the results from the previous section, we have randomly drawn 90 more realistic cloudy profiles directly from the 10000 ICON profiles, which were used to create the mean profile (see Sect. 5.2). The information content $\triangle \mathrm{DOF}$ was calculated in the same way as before. Although an even greater dataset would be desirable, the calculation of the Jacobians with ARTS is numerically rather expensive and we had to trade extensive statistics against computing time.

Figure 12 gives an overview of the information contents for the different hydrometeor types depending on the respective hydrometeor paths in the atmospheric column. The results from the idealized atmosphere presented above are substantiated in this statistical approach. Naturally the system tends to higher information contents for higher mass contents of the respective hydrometeor. The values are in a similar range as they were found above, except for SWC. For SWC, the $\triangle D O F$ from the idealized atmosphere tends towards higher information contents than most of the realistic atmospheres, even though the path is well in the range of paths from those 90 atmospheres. This may be due to the fact that we tried to include all hydrometeor types in the idealized profiles. In most realistic profiles the combination of snow and liquid clouds is rare. Thus, in general we expect to gain slightly less information on SWC than was found for the idealized mean atmosphere.

For cloud ice and snow, high total $\triangle \mathrm{DOF}$ tend to occur for high integrated path values IWP and SWP. For the liquid hydrometeors, a relationship between high paths and high total information content is not found. On the contrary, for LWC the low total $\triangle \mathrm{DOF}$ tend to be at the upper end of LWP, where the cloud is mainly liquid and only 

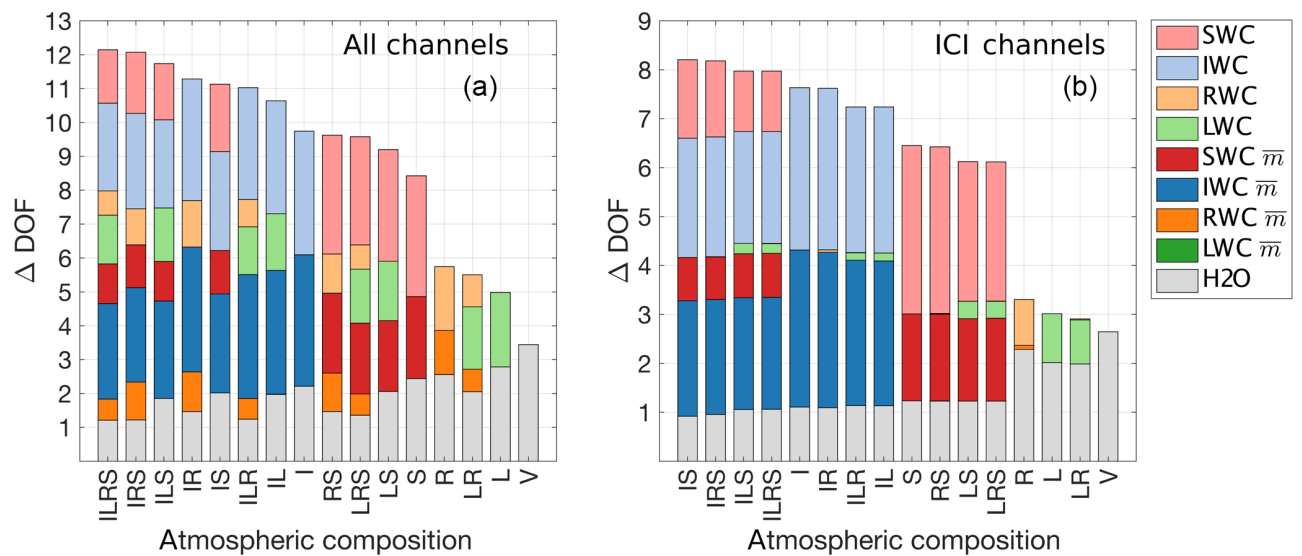

Figure 10. Information content $\triangle \mathrm{DOF}$ for all atmospheres, ranked according to the total $\triangle \mathrm{DOF}$. Results for the full set of channels are shown on the left, results for channels corresponding to ICI are shown on the right. Both were calculated with $\epsilon=0.6$.
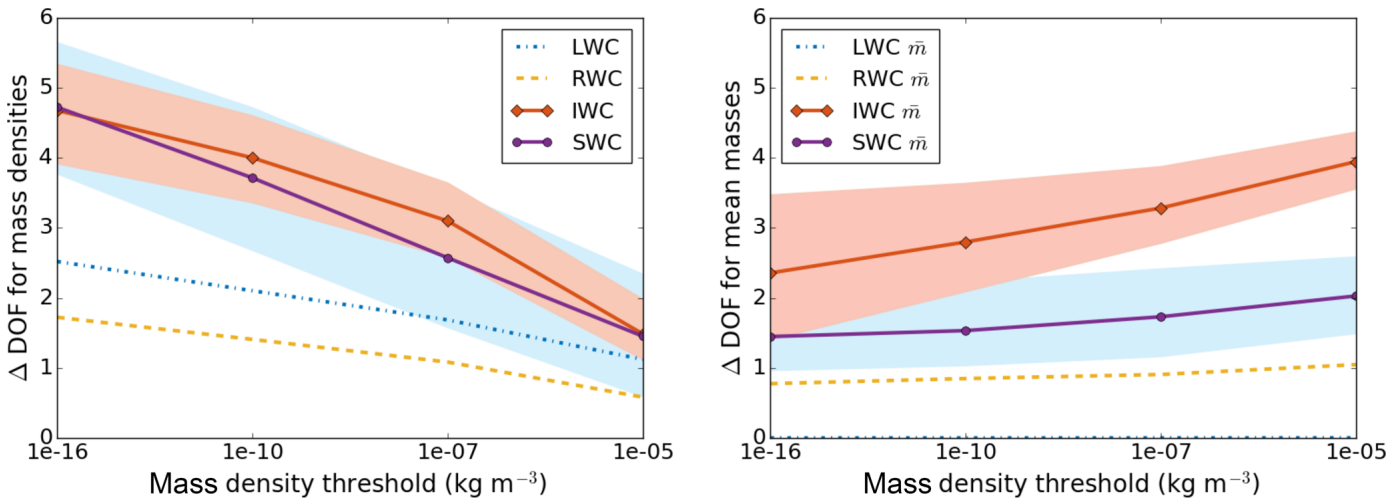

Figure 11. Dependence of information content on the thresholds for the mass density in the calculation of the a priori covariance error (see Sect. 6.3 for details). The lines show the mean information content over the 16 atmospheres, the shaded areas mark the spread between the minimum and maximum information content over the atmospheres for cloud ice (red) and snow (blue).

little frozen water mass is present. If ice is present in the cloud, the liquid hydrometeors will be consumed quickly by the Bergeron-Findeisen process and riming, yielding lower LWPs but higher total $\triangle D O F s$. The overall high information contents gained for frozen hydrometeors again points to the ability of sensors with such high microwave channels to observe ice and snow particles in clouds on a global scale robustly regardless of the atmospheric composition.

Some caution has to be paid with regard to the physical assumptions underlying the scattering and absorption properties of ice particles. For example, Birman et al. (2017) found that changes in the size distribution and scattering properties can shift the information content from IWC to solid precipitation. Also, contrary to this study, Brath et al. (2018) did not find their retrieval was sensitive to IWC using the same channels. They base their analysis on ICON simulations with a one-moment scheme, where the size distributions for IWC and SWC are more distinct and hardly overlap, and where the IWC distribution is shifted to smaller ice particles (Sect. 3.1). Therefore the information content is distributed differently between IWC and SWC. In nature, this arbitrary distinction between IWC and SWC does not exist and we only gain information about the whole set of frozen hydrometeors at once, limited only by the size and amount of the particles, and depending on their shape.

In summary, the analysis of the model atmospheres with their different compositions shows satisfactory results. Despite the strong interdependencies of the Jacobians for cloudy conditions presented in Sect. 6.2 the information content about the frozen hydrometeors proved to be high, independent of the atmospheric composition. This is especially due to the channels at high frequencies, for which the Jacobians peak at different heights. Satellite missions such as ICI on MetOp SG, which employ a set of these high frequency channels therefore have a great potential to provide a robust retrieval of cloud ice and snow. For these frozen hydrometeors, even an estimation of a profile may be possible, because the channels give information about different heights in the atmosphere and we get $\triangle \mathrm{DOFs}$ up to four for IWC, which corresponds to four different heights. Also, especially for cloud 

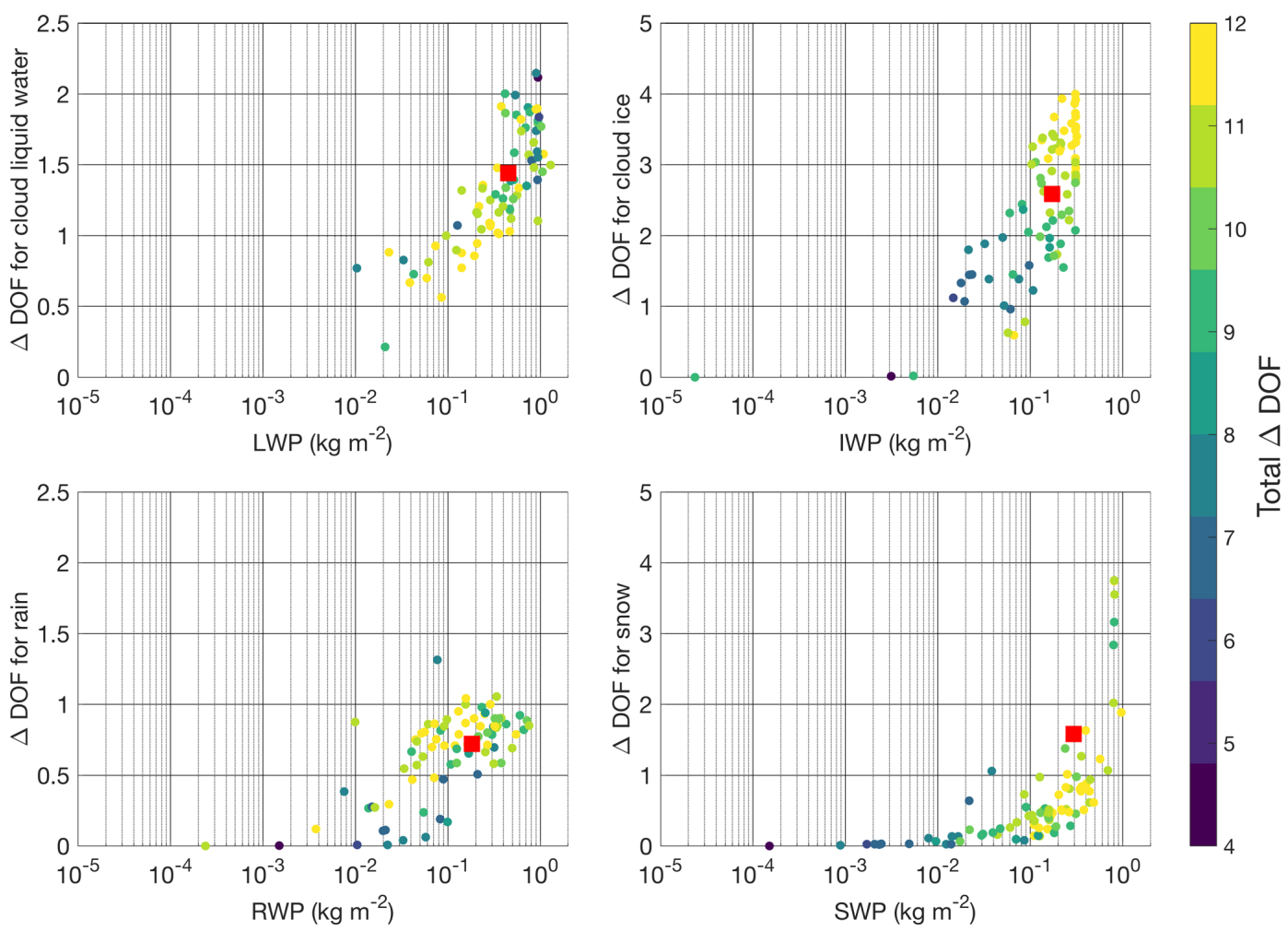

Figure 12. $\triangle \mathrm{DOF}$ for the different hydrometeor mass densities over their respective column integrated path for 90 realistic atmospheres and the idealized atmosphere. The total $\triangle \mathrm{DOF}$ is illustrated by colour. The red square corresponds to the value from the idealized base profile. Note the different $y$ axis for liquid and frozen hydrometeors.

ice, consistently some insight into the microphysical properties is gained, i.e. about the mean particle mass.

To observe liquid hydrometeors, the lower channels from Deimos and Mars proved to be useful. These channels in the regions between 50 and 57 and around $118.75 \mathrm{GHz}$ are employed on MWI on Metop-SG. MWI uses, amongst others, channels in these regions to retrieve precipitation over land and sea (Bauer and Mugnai, 2003).

\section{Conclusions}

In this study, an all-sky information content analysis was performed for passive microwave instruments using channels from the instruments MARSS, Deimos and ISMAR, which range from 23.8 to $874.4 \mathrm{GHz}$. We based the study on an ICON simulation employing the two-moment microphysics scheme by Seifert and Beheng (2006) and calculated Jacobians with the radiative transfer simulator ARTS (Buehler et al., 2005, 2018; Eriksson et al., 2011).

An analysis of idealized profiles from ICON containing different combinations of LWC, IWC, RWC and SWC showed that the Jacobians for the hydrometeors and $\mathrm{H}_{2} \mathrm{O}$ have strong interdependencies. Each component of the cloud changes the radiative background for the others, such that its presence weakens or strengthens their contributions to the measured brightness temperature in the respective channel. The warming signal from $\mathrm{H}_{2} \mathrm{O}$ in the 89.0 and outermost $118.75 \mathrm{GHz}$ channel is weakened by liquid hydrometeors, and the negative signal in the channels higher than 183.31 GHz turns positive in the presence of frozen hydrometeors in the atmospheric column seen by the channel. The signals from LWC and RWC strongly depend on the presence of other hydrometeor types and even change sign in some channels depending on the composition of the atmosphere. The signal from frozen hydrometeors is always negative at all heights. It tends to get stronger in the presence of liquid hydrometeors, which is contrary to the findings of Greenwald and Christopher (2002) for $183.31 \mathrm{GHz}$. The signal from frozen hydrometeors slightly weakens if both frozen hydrometeor types, IWC and SWC, are present at the same time.

Despite these interdependencies of the Jacobians, the information content is robust with regard to the composition of the atmosphere. Due to the higher channels beyond $183.31 \mathrm{GHz}$ the information content on the frozen hydrometeors is high. On average $\triangle \mathrm{DOF}$ reaches 3.10 and 2.57 for IWC and SWC. This implies a potential to retrieve profiles of the frozen hydrometeors and is due to the Jacobians of the relevant channels peaking at different heights. Also, the use of these high frequency channels enables us 
to observe microphysical properties of IWC and SWC. Especially for IWC $\bar{m}$ a high information content of 3.28 is found. The information content found for SWC $\bar{m}$ is lower (1.73). However, one has to keep in mind that the distinction between IWC and SWC in the atmospheric model is inherent in the microphysical parameterization scheme and can not be made in reality, where the transition between the hydrometeors is continuous. Also, the model inherent microphysical size distributions influence the results. For example, the two-moment scheme used in this study tends to larger frozen hydrometeors and fewer small cloud ice particles than for example the one moment scheme from McFarquhar and Heymsfield (1997). As expected, the employed channels below $183 \mathrm{GHz}$ observe mainly the liquid hydrometeors. With the full set of channels, an information content of 1.69 for LWC and of 1.08 for RWC is gained. There is only very little information about the mean mass of the two liquid hydrometeors. However, the focus of this study was on frozen hydrometeors and the channels were chosen accordingly. For a more decent retrieval of liquid water more channels in the lower regions would have to be employed as explained by, for example, Bauer and Mugnai (2003).

We have consolidated the results from the idealized profile with a set of 90 more realistic cloudy profiles from the ICON model. As expected close relation between the hydrometeor path and the information we gain about that hydrometeor was found. The highest total information contents stem from atmospheres containing frozen hydrometeors, which is due to the fact that the scattering signal from IWC and SWC is strong, especially in the higher channels used in this study.

To explore the potential of ICI to observe cloud ice amount and microphysical properties on the global scale we also analysed the all-sky information content gained from that instrument. It was found that the information with regard to IWC (2.76) and SWC (2.27) is only slightly lower than for the full channel set and that there is still information about the microphysical properties of the frozen particles, even though for IWC $\bar{m}$ mean masses it is considerably reduced to 2.70 compared to the full channel value of 3.28. The good performance of the ICI channel set for cloud ice and snow retrievals is very encouraging for the upcoming mission.

Data availability. The data is publicly available at http://doi.org/ 10.5281/zenodo.1309347 (Grützun et al., 2018).

Competing interests. The authors declare that they have no conflict of interest.

Acknowledgements. This work was funded by the European Space Agency (ESA) under the contract Nr. 4000113023/13/NL/MV and by the Universität Hamburg's Cluster of Excellence "Integrated Climate System Analysis and Prediction" (CliSAP, funded by
DFG). The authors thank the Max Planck Institute for Meteorology, Hamburg, and the project $\mathrm{HD}(\mathrm{CP})^{2}$ for providing the atmospheric model data for this study and the ARTS community for providing and developing the radiative transfer model ARTS. We thank Axel Seifert for his support with regard to the two-moment microphysics scheme, Rémy Roca and Jean-François Mahfouf for the very valuable scientific discussions and support, and Oliver Lemke for technical support of the study. Furthermore, the authors would like to thank two anonymous reviewers for their very valuable comments and discussion, especially with regard to the a priori assumptions.

Edited by: Brian Kahn

Reviewed by: two anonymous referees

\section{References}

Accadia, C., Schlüssel, P., Phillips, P. L., and Wilson, J. J. W.: The EUMETSAT Polar System-Second Generation (EPS-SG) microwave and sub-millimetre wave imaging missions, in: SPIE Remote Sensing, International Society for Optics and Photonics, 8889, 8889OH, https://doi.org/10.1117/12.2028676, 2013.

Aires, F., Prigent, C., Orlandi, E., Milz, M., Eriksson, P., Crewell, S., Lin, C.-C., and Kangas, V.: Microwave hyper-spectral measurements for temperature and humidity atmospheric profiling from satellite: the clear-sky case, J. Geophys. Res., 120, 1133411351, https://doi.org/10.1002/2015JD023331, 2015.

Aires, F., Prigent, C., Buehler, S. A., Eriksson, P., Milz, M., and Crewell, S.: Towards more realistic hypotheses for the information content analysis of cloudy/precipitating situations - Application to an hyper-spectral instrument in the microwaves, Q. J. Roy. Meteor. Soc., https://doi.org/10.1002/qj.3315, 2018.

Bauer, P. and Mugnai, A.: Precipitation profile retrievals using temperature-sounding microwave observations, J. Geophys. Res., 108, 4730, https://doi.org/10.1029/2003JD003572, 2003.

Bennartz, R. and Bauer, P.: Sensitivity of microwave radiances at 85-183 GHz to precipitating ice particles, Radio Sci., 38, 8075, https://doi.org/10.1029/2002RS002626, 2003.

Birman, C., Mahfouf, J.-F., Milz, M., Mendrok, J., Buehler, S. A., and Brath, M.: Information content on hydrometeors from millimeter and sub-millimeter wavelengths, Tellus, 69, https://doi.org/10.1080/16000870.2016.1271562, 2017.

Bonsignori, R.: The Microwave Humidity Sounder (MHS): in-orbit performance assessment, Proc. SPIE 6744, Sensors, Systems, and Next-Generation Satellites XI, 67440A (17 October 2007), https://doi.org/10.1117/12.737986, 2007.

Boucher, O., Randall, D., Artaxo, P., Bretherton, C., Feingold, G., Forster, P., Kerminen, V.-M., Kondo, Y., Liao, H., Lohmann, U., Rasch, P., Satheesh, S., Sherwood, S., Stevens, B., and Zhang, X.: Clouds and Aerosols, book section 7, 571-658, Cambridge University Press, Cambridge, UK and New York, NY, USA, https://doi.org/10.1017/CBO9781107415324.016, available at: www.climatechange2013.org (last access: 15 June 2018), 2013.

Brath, M., Fox, S., Eriksson, P., Harlow, R. C., Burgdorf, M., and Buehler, S. A.: Retrieval of an ice water path over the ocean from ISMAR and MARSS millimeter and submillimeter brightness temperatures, Atmos. Meas. Tech., 11, 611-632, https://doi.org/10.5194/amt-11-611-2018, 2018. 
Buehler, S. A., Eriksson, P., Kuhn, T., von Engeln, A., and Verdes, C.: ARTS, the atmospheric radiative transfer simulator, J. Quant. Spectrosc. Ra., 91, 65-93, https://doi.org/10.1016/j.jqsrt.2004.05.051, 2005.

Buehler, S. A., Jiménez, C., Evans, K. F., Eriksson, P., Rydberg, B., Heymsfield, A. J., Stubenrauch, C., Lohmann, U., Emde, C., John, V. O., Sreerekha, T. R., and Davis, C. P.: A concept for a satellite mission to measure cloud ice water path and ice particle size, Q. J. Roy. Meteor. Soc., 133, 109-128, https://doi.org/10.1002/qj.143, 2007.

Buehler, S. A., Defer, E., Evans, F., Eliasson, S., Mendrok, J., Eriksson, P., Lee, C., Jiménez, C., Prigent, C., Crewell, S., Kasai, Y., Bennartz, R., and Gasiewski, A. J.: Observing ice clouds in the submillimeter spectral range: the CloudIce mission proposal for ESA's Earth Explorer 8, Atmos. Meas. Tech., 5, 1529-1549, https://doi.org/10.5194/amt-5-1529-2012, 2012.

Buehler, S. A., Mendrok, J., Eriksson, P., Perrin, A., Larsson, R., and Lemke, O.: ARTS, the Atmospheric Radiative Transfer Simulator - version 2.2, the planetary toolbox edition, Geosci. Model Dev., 11, 1537-1556, https://doi.org/10.5194/gmd-111537-2018, 2018.

Burns, B., Wu, X., and Diak, G.: Effects of precipitation and cloud ice on brightness temperatures in AMSU moisture channels, IEEE. T. Geosci. Remote, 35, 1429-1437, https://doi.org/10.1109/36.649797, 1997.

Defer, E., Galligani, V. S., Prigent, C., and Jimenez, C.: First observations of polarized scattering over ice clouds at close-tomillimeter wavelengths $(157 \mathrm{GHz})$ with MADRAS on board the Megha-Tropiques mission, J. Geophys. Res., 119, 12301-12316, https://doi.org/10.1002/2014JD022353, 2014.

Desbois, M., Roca, R., Eymard, L., Viltard, N., Viollier, M., Srinivasan, J., and Narayanan, S.: The Megha-Tropiques mission, Proc. of SPIE, 4899, 172-183, 2002.

Di Michele, S. and Bauer, P.: Passive microwave radiometer channel selection based on cloud and precipitation information content, Q. J. Roy. Meteor. Soc., 132, 1299-1323, https://doi.org/10.1256/qj.05.164, 2006.

Dipankar, A., Stevens, B., Heinze, R., Moseley, C., Zängl, G., Giorgetta, M., and Brdar, S.: A Large Eddy Simulation version of ICON (ICOsahedral Nonhydrostatic): Model Description and Validation, J. Adv. Model. Earth Sy., 7, 963-986, https://doi.org/10.1002/2015MS000431, 2015.

Duruisseau, F., Chambon, P., Guedj, S., Guidard, V., Fourrié, N., Taillefer, F., Brousseau, P., Mahfouf, J.-F., and Roca, R.: Investigating the potential benefit to a mesoscale NWP model of a microwave sounder on board a geostationary satellite, Q. J. Roy. Meteor. Soc., 143, 2104-2115, https://doi.org/10.1002/qj.3070, 2017.

Emde, C., Buehler, S. A., Davis, C., Eriksson, P., Sreerekha, T. R., and Teichmann, C.: A Polarized Discrete Ordinate Scattering Model for Simulations of Limb and Nadir Longwave Measurements in 1-D/3-D Spherical Atmospheres, J. Geophys. Res., 109, D24207, https://doi.org/10.1029/2004JD005140, 2004.

Eriksson, P., Ekström, M., Rydberg, B., Wu, D. L., Austin, R. T., and Murtagh, D. P.: Comparison between early Odin-SMR, Aura MLS and CloudSat retrievals of cloud ice mass in the upper tropical troposphere, Atmos. Chem. Phys., 8, 1937-1948, https://doi.org/10.5194/acp-8-1937-2008, 2008.
Eriksson, P., Buehler, S. A., Davis, C. P., Emde, C., and Lemke, O.: ARTS, the atmospheric radiative transfer simulator, Version 2, J. Quant. Spectrosc. Ra., 112, 1551-1558, https://doi.org/10.1016/j.jqsrt.2011.03.001, 2011.

Eriksson, P., Jamali, M., Mendrok, J., and Buehler, S. A.: On the microwave optical properties of randomly oriented ice hydrometeors, Atmos. Meas. Tech., 8, 1913-1933, https://doi.org/10.5194/amt-8-1913-2015, 2015.

Fox, S., Lee, C., Moyna, B., Philipp, M., Rule, I., Rogers, S., King, R., Oldfield, M., Rea, S., Henry, M., Wang, H., and Harlow, R. C.: ISMAR: an airborne submillimetre radiometer, Atmos. Meas. Tech., 10, 477-490, https://doi.org/10.5194/amt-10-4772017, 2017.

Geer, A. J. and Baordo, F.: Improved scattering radiative transfer for frozen hydrometeors at microwave frequencies, Atmos. Meas. Tech., 7, 1839-1860, https://doi.org/10.5194/amt-7-1839-2014, 2014.

Geer, A., Baordo, F., Bormann, N., Chambon, P., English, S., Kazumori, M., Lawrence, H., Lean, P., Lonitz, K., and Lupu, C.: The growing impact of satellite observations sensitive to humidity, cloud and precipitation, Q. J. Roy. Meteor. Soc., 143, 3189-3206, 2017.

Greenwald, T. J. and Christopher, S. A.: Effect of cold clouds on satellite measurements near $183 \mathrm{GHz}$, J. Geophys. Res., 107, D13, https://doi.org/10.1029/2000JD000258, 2002.

Grützun, V., Buehler, S. A., Kluft, L., Mendrok, J., Brath, M., and Eriksson, P.: All-sky information content analysis for novel passive microwave instruments - data (Version 1.0.0) [Data set], Zenodo, https://doi.org/10.5281/zenodo.1309347, 2018.

Guerbette, J., Mahfouf, J.-F., and Plu, M.: Towards the assimilation of all-sky microwave radiances from the SAPHIR humidity sounder in a limited area NWP model over tropical regions, Tellus A, Dynamic Meteorology and Oceanography, 68, https://doi.org/10.3402/tellusa.v68.28620, 2016.

Heinze, R., Dipankar, A., Henken, C. C., Moseley, C., Sourdeval, O., Troemel, S., Xie, X., Adamidis, P., Ament, F., Baars, H., Barthlott, C., Behrendt, A., Blahak, U., Bley, S., Brdar, S., Brueck, M., Crewell, S., Deneke, H., Di Girolamo, P., Evaristo, R., Fischer, J., Frank, C., Friederichs, P., Goecke, T., Gorges, K., Hande, L., Hanke, M., Hansen, A., Hege, H.-C., Hoose, C., Jahns, T., Kalthoff, N., Klocke, D., Kneifel, S., Knippertz, P., Kuhn, A., van Laar, T., Macke, A., Maurer, V., Mayer, B., Meyer, C. I., Muppa, S. K., Neggers, R. A. J., Orlandi, E., Pantillon, F., Pospichal, B., Roeber, N., Scheck, L., Seifert, A., Seifert, P., Senf, F., Siligam, P., Simmer, C., Steinke, S., Stevens, B., Wapler, K., Weniger, M., Wulfmeyer, V., Zaengl, G., Zhang, D., and Quaas, J.: Large-eddy simulations over Germany using ICON: a comprehensive evaluation, Q. J. Roy. Meteor. Soc., 143, 69-100, https://doi.org/10.1002/qj.2947, 2017.

Hewison, T.: The design of Deimos: a microwave radiometer with channels at $23.8 \mathrm{GHz}$ and $50.3 \mathrm{GHz}$ for the UK Met. Research Flight C-130 aircraft, in: International Geoscience and Remote Sensing Symposium "Quantitative Remote Sensing for Science and Applications", Firenze, Italy, vol. 3, 2261-2263, https://doi.org/10.1109/IGARSS.1995.524165, 1995.

Heymsfield, A. J.: On measurements of small ice particles in clouds, Geophys. Res. Lett., 34, 123812 , https://doi.org/10.1029/2007GL030951, 2007. 
Hong, G., Heygster, G., Miao, J., and Kunzi, K.: Sensitivity of microwave brightness temperatures to hydrometeors in tropical deep convective cloud system at 89$190 \mathrm{GHz}$ channels measurements, Radio Sci., 40, RS4003, https://doi.org/10.1029/2004RS003129, 2005.

Hong, G., Yang, P., Baum, B. A., Heymsfield, A. J., Weng, F., Liu, Q., Heygster, G., and Buehler, S. A.: Scattering Database in the Millimeter and Submillimeter Wave Range of $100-1000 \mathrm{GHz}$ for Nonspherical Ice Particles, J. Geophys. Res., 114, D06201, https://doi.org/10.1029/2008JD010451, 2009.

Jiménez, C., Buehler, S. A., Rydberg, B., Eriksson, P., and Evans, K. F.: Performance simulations for a submillimetre wave cloud ice satellite instrument, Q. J. Roy. Meteor. Soc., 133, 129-149, https://doi.org/10.1002/qj.134, 2007.

Karouche, N., Goldstein, C., Rosak, A., Malassingne, C., and Raju, G.: "MEGHA-TROPIQUES satellite mission: In flight performances results", Proc. IEEE IGARSS, 4684-4687, July 2012.

Liu, G.: A Database of Microwave Single-Scattering Properties for Nonspherical Ice Particles, B. Am. Meteorol. Soc., 89, 15631570, https://doi.org/10.1175/2008BAMS2486.1, 2008.

Macke, A., Seifert, P., Baars, H., Barthlott, C., Beekmans, C., Behrendt, A., Bohn, B., Brueck, M., Bühl, J., Crewell, S., Damian, T., Deneke, H., Duesing, S., Foth, A., Di Girolamo, P., Hammann, E., Heinze, R., Hirsikko, A., Kalisch, J., Kalthoff, N., Kinne, S., Kohler, M., Löhnert, U., Madhavan, B. L., Maurer, V., Muppa, S. K., Schween, J., Serikov, I., Siebert, H., Simmer, C., Späth, F., Steinke, S., Träumner, K., Trömel, S., Wehner, B., Wieser, A., Wulfmeyer, V., and Xie, X.: The $\operatorname{HD}(\mathrm{CP})(2) \mathrm{Ob}-$ servational Prototype Experiment (HOPE) - an overview, Atmos. Chem. Phys., 17, 4887-4914, https://doi.org/10.5194/acp17-4887-2017, 2017.

Mahfouf, J.-F., Birman, C., Aires, F., Prigent, C., Orlandi, E., and Milz, M.: Information content on temperature and water vapour from a hyper-spectral microwave sensor, Q. J. Roy. Meteor. Soc., 141, 3268-3284, https://doi.org/10.1002/qj.2608, 2015.

Mätzler, C.: MATLAB functions for Mie scattering and absorption, version 2, IAP Res. Rep., 8, 18 pp., 2002.

Mätzler, C.: Thermal Microwave Radiation: Application for Remote Sensing, vol. 52 of IET Electromagn. Waves Ser., chap. Microwave dielectric properties of ice, Inst. Eng. Technol., 455462, Stevenage, UK, 2006.

McFarquhar, G. M. and Heymsfield, A. J.: Parameterization of Tropical Cirrus Ice Crystal Size Distribution and Implications for Radiative Transfer: Results from CEPEX, J. Atmos. Sci., 54, 2187-2200, https://doi.org/10.1175/15200469(1997)054<2187:POTCIC>2.0.CO;2, 1997.

McGrath, A. and Hewison, T.: Measuring the Accuracy of MARSS - An Airborne Microwave Radiometer, J. Atmos. Ocean Technol., 18, 2003-2012, 2001.

Mlawer, E. J., Payne, V. H., Moncet, J.-L., Delamere, J. S., Alvarado1, M. J., and Tobin, D. C.: Development and recent evaluation of the MT_CKD model of continuum absorption, Phil. Trans. R. Soc. A, 370, 2520-2556, https://doi.org/10.1098/rsta.2011.0295, 2012.

Muller, B. M., Fuelberg, H. E., and Xiang, X.: Simulations of the Effects of Water Vapor, Cloud Liquid Water, and Ice on AMSU Moisture Channel Brightness Temperatures, J. Appl. Meteorol., 33, 1133-1154, 1994.
Pica, G., Alberti, G., Memoli, A., Santovito, M. R., Varchetta, S., Buralli, B., D'Addio, S., and Kangas, V.: MetOp Second Generation: A joint ESA/EUMETSAT mission for weather forecast and climate monitoring with an imaging radiometer, in: Proceedings of the 63rd International Astronautical Congress 2012 (IAC 2012), International Astronautical Federation (IAF), 3132-3136, paper: IAC-12-B1.3.10, 2012.

Rodgers, C. D. (Ed.): Inverse Methods for Atmospheric Sounding: Theory and Practice, World Scientific Publishing Co Pte Ltd, 111, https://doi.org/10.1142/9789812813718_0001, 2011.

Rothman, L. S., Gordon, I. E., Babikov, Y., Barbe, A., Benner, D. C., Bernath, P. F., Birk, M., Bizzocchi, L., Boudon, V., Brown, L. R., Campargue, A., Chance, K., Cohen, E. A., Coudert, L. H., Devi, V. M., Drouin, B. J., Fayt, A., Flaud, J.-M., Gamache, R. R., Harrison, J. J., Hartmann, J.-M., Hill, C., Hodges, J. T., Jacquemart, D., Jolly, A., Lamouroux, J., Le Roy, R. J., Li, G., Long, D. A., Lyulin, O. M., Mackie, C. J., Massie, S. T., Mikhailenko, S., Müller, H. S. P., Naumenko, O. V., Nikitin, A. V., Orphal, J., Perevalov, V., Perrin, A., Polovtseva, E. R., Richard, C., Smith, M. A. H., Starikova, E., Sung, K., Tashkun, S., Tennyson, J., Toon, G. C., Tyuterev, V. G., and Wagner, G.: The HITRAN2012 molecular spectroscopic database, J. Quant. Spectrosc. Ra., 130, 4-50, https://doi.org/10.1016/j.jqsrt.2013.07.002, 2013.

Seifert, A. and Beheng, K. D.: A two-moment cloud microphysics parameterization for mixed-phase clouds. Part 1: Model description, Meteorol. Atmos. Phys., 92, 45-66, https://doi.org/10.1007/s00703-005-0112-4, 2006.

Sreerekha, T. R., Buehler, S. A., O'Keeffe, U., Doherty, A., Emde, C., and John, V. O.: A strong ice cloud event as seen by a microwave satellite sensor: Simulations and Observations, J. Quant. Spectrosc. Ra., 109, 1705-1718, https://doi.org/10.1016/j.jqsrt.2007.12.023, 2008.

Stamnas, E., Lammert, A., Winkelmann, V., and Lang, U.: The $\mathrm{HD}(\mathrm{CP}) 2$ Data Archive for Atmospheric Measurement Data, ISPRS Int. Geo.-Inf., 5, 124, https://doi.org/10.3390/ijgi5070124, 2016.

Wan, H., Giorgetta, M. A., Z angl, G., Restelli, M., Majewski, D., Bonaventura, L., Fröhlich, K., Reinert, D., Rípodas, P., Kornblueh, L., and Förstner, J.: The ICON-1.2 hydrostatic atmospheric dynamical core on triangular grids - Part 1: Formulation and performance of the baseline version, Geosci. Model Dev., 6, 735-763, https://doi.org/10.5194/gmd-6-735-2013, 2013.

Warren, S.: Optical Constants of Ice from the Ultraviolet to the Microwave, Appl. Opt., 23, 1206-1225, https://doi.org/10.1364/AO.23.001206, 1984.

Weng, F., Zhao, L., Ferraro, R. R., Poe, G., Li, X., and Grody, N. C.: Advanced microwave sounding unit cloud and precipitation algorithms, Radio Sci., 38, 8068, https://doi.org/10.1029/2002RS002679, 2003.

Zhao, L. and Weng, F.: Retrieval of Ice Cloud Parameters Using the Advanced Microwave Sounding Unit, J. Appl. Meteorol., 41, 384-395, 2002. 